\title{
Modelling of hydrogen transport in silicon solar cell structures under equilibrium conditions
}

Cite as: J. Appl. Phys. 123, 043108 (2018); https://doi.org/10.1063/1.5016854

Submitted: 21 November 2017 . Accepted: 07 January 2018 . Published Online: 26 January 2018

P. Hamer, B. Hallam, R. S. Bonilla (D, P. P. Altermatt, P. Wilshaw, and S. Wenham

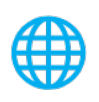

\section{ARTICLES YOU MAY BE INTERESTED IN}

Light-induced activation and deactivation of bulk defects in boron-doped float-zone silicon Journal of Applied Physics 121, 185702 (2017); https://doi.org/10.1063/1.4983024

Recombination parameters of lifetime-limiting carrier-induced defects in multicrystalline silicon for solar cells

Applied Physics Letters 110, 092106 (2017); https://doi.org/10.1063/1.4977906

Impact of interstitial iron on the study of meta-stable B-O defects in Czochralski silicon:

Further evidence of a single defect

Journal of Applied Physics 123, 161586 (2018); https://doi.org/10.1063/1.5000323

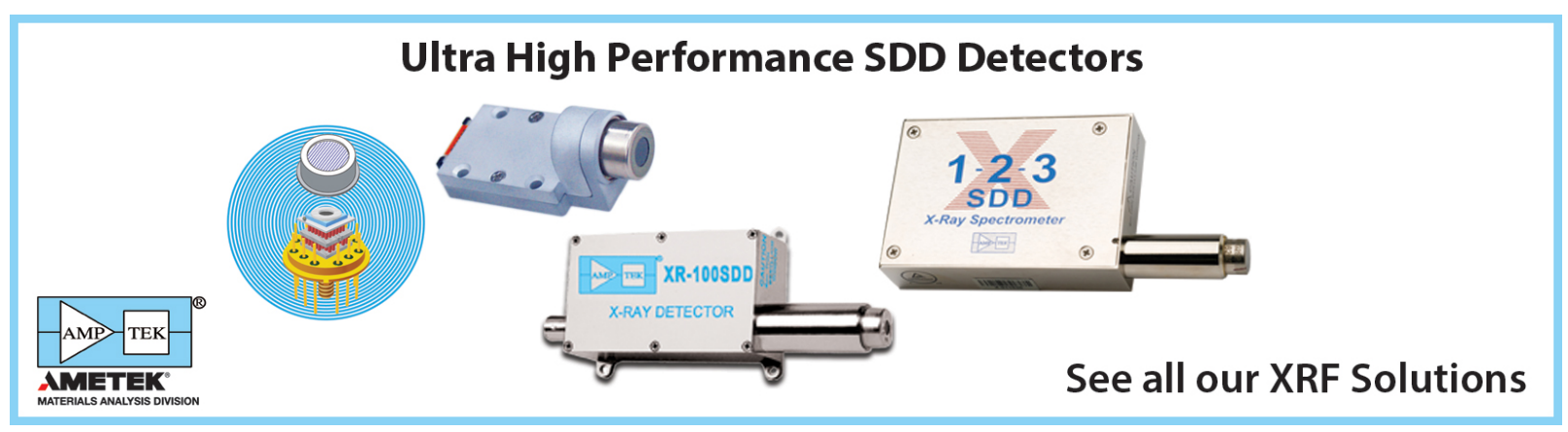




\title{
Modelling of hydrogen transport in silicon solar cell structures under equilibrium conditions
}

\author{
P. Hamer, ${ }^{1,2, a)}$ B. Hallam, ${ }^{2}$ R. S. Bonilla, ${ }^{1}$ P. P. Altermatt, ${ }^{3}$ P. Wilshaw, ${ }^{1}$ and S. Wenham ${ }^{2}$ \\ ${ }^{1}$ Department of Materials, University of Oxford, Oxford OX1 3PH, United Kingdom \\ ${ }^{2}$ School of Photovoltaic and Renewable Energy Engineering, University of New South Wales, Sydney, \\ New South Wales 2052, Australia \\ ${ }^{3}$ Trina Solar, State Key Laboratory of PV Science and Technology, Changzhou, Jiangsu Province 213031, \\ China
}

(Received 21 November 2017; accepted 7 January 2018; published online 26 January 2018)

\begin{abstract}
This paper presents a model for the introduction and redistribution of hydrogen in silicon solar cells at temperatures between 300 and $700^{\circ} \mathrm{C}$ based on a second order backwards difference formula evaluated using a single Newton-Raphson iteration. It includes the transport of hydrogen and interactions with impurities such as ionised dopants. The simulations lead to three primary conclusions: (1) hydrogen transport across an n-type emitter is heavily temperature dependent; (2) under equilibrium conditions, hydrogen is largely driven by its charged species, with the switch from a dominance of negatively charged hydrogen $\left(\mathrm{H}^{-}\right)$to positively charged hydrogen $\left(\mathrm{H}^{+}\right)$ within the emitter region critical to significant transport across the junction; and (3) hydrogen transport across n-type emitters is critically dependent upon the doping profile within the emitter, and, in particular, the peak doping concentration. It is also observed that during thermal processes after an initial high temperature step, hydrogen preferentially migrates to the surface of a phosphorous doped emitter, drawing hydrogen out of the p-type bulk. This may play a role in several effects observed during post-firing anneals in relation to the passivation of recombination active defects and even the elimination of hydrogen-related defects in the bulk of silicon solar cells. Published by AIP Publishing. https://doi.org/10.1063/1.5016854
\end{abstract}

\section{INTRODUCTION}

The use of hydrogen $(\mathrm{H})$ to passivate bulk defects in silicon solar cells is a well-established technique that has been demonstrated to result in significant increases in bulk carrier lifetimes, ${ }^{1-3}$ with increases of over an order of magnitude reported. ${ }^{4,5}$ In order to better understand and control these processes, it is important to understand the transport of hydrogen within silicon, in particular, how it is affected by doping profiles and internal electric fields in solar cell architectures.

Hydrogen passivation of commercial solar cells has traditionally taken place at temperatures in excess of $800^{\circ} \mathrm{C}$, with hydrogen introduced to the structure from a hydrogenated silicon nitride $\left(\mathrm{SiN}_{\mathrm{X}}: \mathrm{H}\right)$ layer during firing of screenprinted metal contacts. ${ }^{1,6}$ In contrast, several alternative cell technologies either cannot, or would prefer not to, use high temperature processing. ${ }^{7-9}$ This creates significant challenges, not only in terms of releasing hydrogen from dielectric films, but in the effective transport of hydrogen within the silicon itself. ${ }^{10}$ It is also instructive to examine how hydrogen introduced during a high temperature firing step may redistribute during subsequent thermal processing. There have been a number of recently developed techniques that use intermediate temperature $\left(300-700^{\circ} \mathrm{C}\right)$ processing to perform low temperature gettering of impurities, ${ }^{11,12}$ or to alleviate degradation in crystalline solar cells. ${ }^{10,13-18}$

\footnotetext{
${ }^{\text {a) }}$ Author to whom correspondence should be addressed: phillip.hamer@ materials.ox.ac.uk
}

Processing at these temperatures would be expected to lead to a significant redistribution of hydrogen within the device, in particular between the emitter and bulk regions.

The introduction and redistribution of hydrogen at these temperatures are of interest not merely due to hydrogen passivation of defects, but because it has recently been suggested that hydrogen can also be linked to the formation of recombination active defects. ${ }^{19,20}$ This includes those responsible for carrier-induced degradation in both monoand multi-crystalline silicon: ${ }^{13,16,21}$ first, in the region $0.3-0.8 \mu \mathrm{m}$ below the $\mathrm{Si} / \mathrm{SiN}_{\mathrm{x}}$ interface ${ }^{22}$ leading to a characteristic recombination behaviour, ${ }^{23}$ second, a build-up at contact/silicon interfaces. ${ }^{24}$

Dopant-hydrogen interactions, ${ }^{25-28}$ and more recently, the formation of hydrogen dimers, ${ }^{29,30}$ have been modelled at temperatures up to $300^{\circ} \mathrm{C}$. However, the charge state transitions and electric field interactions, both in terms of drift of hydrogen ions and the effects of hydrogen ions and dopant deactivation, have not been adequately dealt with for different dopant profiles. Furthermore, the motion of hydrogen at intermediate temperatures is poorly understood. Commercial and research attention has typically been on the introduction of hydrogen from dielectrics at temperatures above $800^{\circ} \mathrm{C}^{1,4,6}$ In contrast, studies on hydrogen dopant interactions typically only range up to $300^{\circ} \mathrm{C}$, due to the relatively low binding energies of hydrogen with the typical dopants used in crystalline silicon, namely boron and phosphorous. ${ }^{25-28}$

Of particular importance for transport of hydrogen at these temperatures are the interactions of hydrogen with dopants and electric fields within silicon. This in turn is 
determined by the charge state of the hydrogen within the silicon, which has been the subject of a number of recent studies. 4,31,32 The properties of highly phosphorus-doped emitter regions in traditional p-type solar cells have been observed to have a marked influence on hydrogen passivation of the bulk silicon, ${ }^{33-35}$ while hydrogen bonding with dopant ions is capable of substantially changing the effective doping. ${ }^{36,37}$ This paper will present modelling on the introduction and redistribution of hydrogen at temperatures between 300 and $700{ }^{\circ} \mathrm{C}$ in silicon solar cells. In particular, it will focus on hydrogen transport and interactions within the silicon itself, with a cursory examination of how hydrogen enters the silicon from an external source. The main uncertainties of the model parameters and outcomes will be discussed and implications will be identified for industrial cell fabrication processes.

\section{HYDROGEN SOURCES}

There are two primary methods for introducing hydrogen into silicon cells: first, the incumbent technology where $\mathrm{H}$ is released from a dielectric layer, typically $\mathrm{SiN}_{\mathrm{X}}: \mathrm{H}$, at the cell's surface. This release is highly temperature dependent. $^{38,39}$ Second, exposing the cells to a hydrogen containing plasma. ${ }^{40-43}$ This reduces the temperature dependence of the hydrogen source; however, it does not provide a passivation layer and can induce damage. ${ }^{42,43}$

\section{A. Hydrogen from dielectrics}

The most common dielectric sources of hydrogen for silicon solar cells are hydrogenated silicon nitride and aluminium oxide $\left(\mathrm{AlO}_{\mathrm{X}}: \mathrm{H}\right)$ layers. These may be deposited using chemical vapour deposition, in particular, plasma enhanced chemical vapour deposition (PECVD) or in the case of $\mathrm{AlO}_{\mathrm{X}}: \mathrm{H}$ through atomic layer deposition (ALD). ${ }^{44-46}$ The amount of hydrogen incorporated into these layers has been reported at up to $30 \%$ atomic for $\mathrm{SiN}_{\mathrm{X}}: \mathrm{H}$ and $12 \%$ for $\mathrm{AlO}_{\mathrm{X}}: \mathrm{H}$, depending upon the deposition techniques and processing parameters. ${ }^{4,48}$

The lower concentration of hydrogen in $\mathrm{AlO}_{\mathrm{X}}: \mathrm{H}$ compared with $\mathrm{SiN}_{\mathrm{X}}: \mathrm{H}$ has led some authors to assume that it acts as a less effective source of hydrogen. However, most available evidence indicates the opposite to be the case at temperatures below $500^{\circ} \mathrm{C}$, where $\mathrm{AlO}_{\mathrm{X}}: \mathrm{H}$ layers have been observed to release significant quantities of hydrogen. ${ }^{49}$ In contrast, most commercial $\mathrm{SiN}_{\mathrm{X}}: \mathrm{H}$ layers are deposited such that they will not release significant hydrogen unless annealed at temperatures above $600^{\circ} \mathrm{C}$, to ensure compatibility with screen-printed firing processes. $^{38,39}$ It is, however, feasible to alter the deposition parameters of PECVD $\mathrm{SiN}_{\mathrm{X}}: \mathrm{H}$ to increase hydrogen release at lower temperatures. ${ }^{50,51}$

While characterisation of the hydrogen content via infra-red absorption spectra has proved effective for determining how much hydrogen has been released during firing, it is still unclear exactly how much hydrogen enters the silicon. It is generally agreed that the majority of hydrogen released escapes to atmosphere in gas form; ${ }^{39,52-55}$ however, the exact proportion entering the silicon and the temperature and nitride deposition parameter dependences of this fraction are still open to debate.

One option for increasing the quantity of hydrogen introduced from a dielectric layer at low temperatures is the application of an electric field. Hydrogen is reported to exist in a charge state in almost all dielectrics, and, in particular, in the positive state in $\mathrm{AlO}_{\mathrm{X}}, \mathrm{SiO}_{\mathrm{X}}$ and $\mathrm{SiN}_{\mathrm{X}}$ layers. ${ }^{56}$ Therefore, the application of an electric field may greatly increase the amount of hydrogen entering the silicon. This may be achieved either through corona charge deposition or through the application of a bias voltage to contacts deposited on the dielectric and on the rear contact of the device. The ability to drift hydrogen through $\mathrm{SiO}_{\mathrm{X}}$ at room temperature has been established for decades, ${ }^{57,58}$ although to date there has been little investigation on dielectrics typically used for solar applications.

\section{B. Plasma sources}

The use of hydrogen containing plasmas avoids issues with temperature dependence of hydrogen release, and has also been shown to be capable of introducing very high fluxes of atomic hydrogen. While initial work introduced hydrogen from a plasma in direct contact with the silicon, ${ }^{27,59}$ the damage caused by bombardment of high energy ions and UV radiation makes it inappropriate for use with silicon solar cells. A remote hydrogen plasma has been demonstrated to avoid the majority of these problems, by confining the plasma in such a way that there is no direct line of sight between the plasma and the samples. ${ }^{40}$ However, some damage has still been observed at temperatures below $300^{\circ} \mathrm{C}$, though how much of this is due to the residual energy of the hydrogen radicals is unclear. ${ }^{41}$

This approach has been used with success for the passivation of thin crystalline solar cells and more recently with the passivated contacts and heterojunction structures. ${ }^{60-62}$ Industrial scale remote plasma systems have been demonstrated to be capable of delivering more than $3 \times 10^{13}$ hydrogen atoms $/ \mathrm{cm}^{2} / \mathrm{s}$ to a silicon sample. ${ }^{41}$

\section{Parameters used in this work}

Since the focus of this work is the behaviour of hydrogen within the silicon itself, it will be assumed that the flux of atomic hydrogen entering the silicon surface is constant and temperature independent, and out-diffusion will be ignored. This allows direct comparison of transport in the silicon bulk at different temperatures, and avoids complications arising from different surface fluxes. A more complex model containing out-diffusion kinetics and the motion of hydrogen within dielectric films would be required for accurate predictions in industrial cells and is intended as part of future development of this model.

For the simulations in this paper, a constant flux of $1 \times 10^{13}$ atoms $/ \mathrm{cm}^{2} / \mathrm{s}$ interstitial hydrogen is maintained at the front surface. While this value is somewhat higher than most atomic hydrogen sources are reported to be capable of, it allows rapid simulation of hydrogen transport within the silicon itself. While other values may be used, it is expected 
that this would primarily affect the timescale, rather than the general behaviours observed.

\section{HYDROGEN TRANSPORT IN SILICON}

Although finding appropriate sources for introducing hydrogen to silicon at temperatures below $700{ }^{\circ} \mathrm{C}$ can be challenging, the lower temperatures also create difficulties in effectively transporting hydrogen throughout the silicon material. In the following, we show that undesirable buildups of hydrogen can occur in near-surface regions, while minimal hydrogen migrates into the silicon bulk to passivate defects. This behaviour is largely driven by the various charge states of interstitial hydrogen and their interaction with impurities and defects within silicon solar cell structures.

\section{A. Hydrogen charge states}

It is generally agreed that hydrogen transport is largely in the interstitial form ${ }^{29,63}$ and hence its motion is complicated by its amphoteric nature -i.e., that $\mathrm{H}$ can exist in positive, negative and neutral charge states in crystalline silicon (denoted $\mathrm{H}^{+}, \mathrm{H}^{0}$, and $\mathrm{H}^{-}$respectively), depending upon local electron and hole concentrations. The equilibrium charge state fractions may be calculated using the donor and acceptor energy levels for hydrogen in silicon, reported as ${ }^{63}$

$$
\begin{aligned}
& E_{D}=E_{C}-0.16 \mathrm{eV}, \\
& E_{A}=E_{V}+0.48 \mathrm{eV} .
\end{aligned}
$$

Hence, the resulting equilibrium charge state fractions depend upon the Fermi energy, as shown in Fig. 1 for temperatures of 300 and $700{ }^{\circ} \mathrm{C}$, calculated after Refs. 31 and 63. A clear cross-over is visible at a system Fermi level just less than $0.2 \mathrm{eV}$ above mid-bandgap, above which $\mathrm{H}^{-}$is dominant and below which $\mathrm{H}^{+}$is dominant. This is also nearly co-incident with the Fermi level for the maximum fractional concentration of $\mathrm{H}^{0}$. More recently, the model has been updated to include non-equilibrium conditions, initially assuming a primary dependence upon the electron

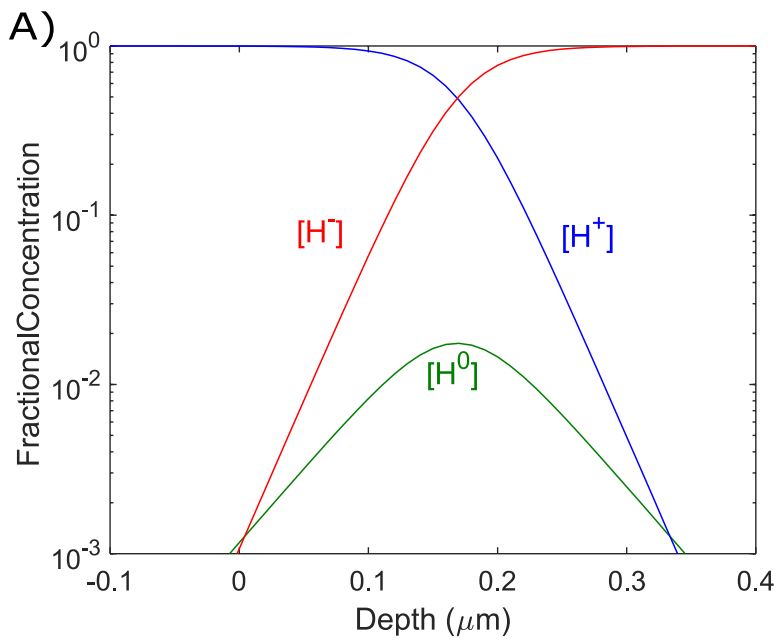

quasi-Fermi energy ${ }^{4,32}$ and subsequently using a SahShockley model. ${ }^{31}$ The drawback of the Sah-Shockley model is the need to know the capture cross-section ratios for the donor and acceptor states. As there are no experimental data available for these values, Sun et al. ${ }^{31}$ used approximations based on the behaviour of metallic impurities

$$
\begin{gathered}
\frac{\sigma_{n}}{\sigma_{p}}=1 \text { for } E_{D}, \\
\frac{\sigma_{n}}{\sigma_{p}}=0.05 \text { for } E_{A} .
\end{gathered}
$$

While this is reasonable for interstitial metallic impurities, it is not clear how well this applies to hydrogen in silicon, and a significant change in these ratios will result in substantially different behaviour of $\mathrm{H}$ in silicon. In particular, the ability to generate $\mathrm{H}^{-}$in p-type silicon under high-injection conditions is minimal with the ratios in (3) and (4), due to the much stronger interaction of the acceptor level with holes compared with that of electrons. If the capture cross-section ratio for $E_{\mathrm{A}}$ is increased, then it becomes possible to have significant fractional $\mathrm{H}^{-}$concentrations in p-type silicon. However, to date, there has been no detailed experimental observation of these effects, and thus, for this work, we use the model of Sun et al. ${ }^{31}$ with no modification of the capture cross-sections.

The use of a non-equilibrium model for hydrogen charge state transitions is not required for the simulations presented in this work, which are all at equilibrium. However, the use of the sah-shockley model is not computationally expensive and will allow future simulations to consider nonequilibrium conditions.

\section{B. Hydrogen diffusivity and mobility}

The reported diffusivities of hydrogen in the different charge states spans several orders of magnitude, ${ }^{17-20}$ especially in the case of $\mathrm{H}^{0}$. Consensus on exact values, and which species diffuse more rapidly, has not been obtained. A number of investigations have been carried out, with the

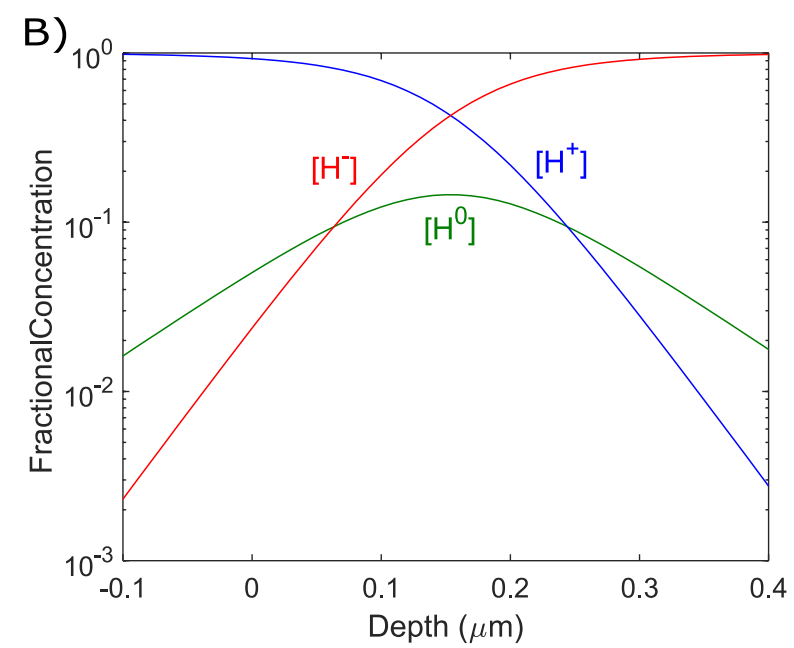

FIG. 1. Fraction of hydrogen in neutral $\left(\mathrm{H}^{0}\right)$, negative $\left(\mathrm{H}^{-}\right)$and positive $\left(\mathrm{H}^{+}\right)$charge states as a function of Fermi level $($relative to the middle of the bandgap) (a) at $300^{\circ} \mathrm{C}$ and (b) at $700^{\circ} \mathrm{C}$. Calculated after Ref. 31. 
work of Van Wieringen and Warmoltz (VWW $)^{64}$ at temperatures between 1000 and $1200^{\circ} \mathrm{C}$ often cited as an upper limit for the diffusivity of hydrogen in defect-free silicon. At lower temperatures, a large range of diffusivities has been reported, depending upon the doping concentration of the silicon and the temperature. ${ }^{42,65-69}$ These discrepancies are largely due to the interaction of hydrogen with a multitude of impurities or defects within crystalline silicon, meaning that in many cases, what is measured is trap-limited diffusion of hydrogen. ${ }^{68,70}$

There is general agreement on the diffusivity of $\mathrm{H}^{+}$with activation energies reported between 0.43 and $0.48 \mathrm{eV}{ }^{64,67,71}$ The diffusivity of $\mathrm{H}^{-}$is much less clear. Johnson and Herring ${ }^{69}$ determined a diffusivity activation energy of $0.7 \mathrm{eV}$ at temperatures between 27 and $47^{\circ} \mathrm{C}$; however, a more recent theoretical calculation by Estreicher et al. ${ }^{67}$ obtained an energy barrier of just $0.39 \mathrm{eV}$ for diffusion of $\mathrm{H}^{-}$. Unambiguous observation of the diffusion of $\mathrm{H}^{-}$ at elevated temperatures has thus far proved challenging due to interaction with other elements in silicon.

Determining the appropriate diffusivity for $\mathrm{H}^{0}$ is even more problematic. Not only is the proportion of hydrogen in the neutral charge state generally much lower than that in other charge states, but it has been suggested that it can be found at both the bond-centred and tetrahedral site within the silicon lattice. While the bond-centred site is the minimum energy location for both $\mathrm{H}^{+}$and $\mathrm{H}^{0}, \mathrm{H}^{-}$is usually found at the tetrahedral site, ${ }^{63,67}$ and so $\mathrm{H}^{0}$ formed from $\mathrm{H}^{-}$will be at this location. Determinations of how much $\mathrm{H}^{0}$ is at the tetrahedral $\left(\mathrm{H}_{\mathrm{T}}^{0}\right)$ compared with the bond-centred $\left(\mathrm{H}_{\mathrm{BC}}^{0}\right)$ site have not yet been reported. Theoretical calculations on $\mathrm{H}_{\mathrm{T}}^{0}$ have predicted that it should be metastable and migrate very rapidly through the lattice (with an activation energy of $0.14 \mathrm{eV}) .{ }^{67}$ The rapid migration of $H_{T}^{0}$ has also been inferred from low temperature DLTS measurements. ${ }^{72}$ In contrast, the migration of $\mathrm{H}_{\mathrm{BC}}^{0}$ is expected to be closer to that of $\mathrm{H}^{+}$ with a theoretical activation energy of $0.38 \mathrm{eV}^{67}$

For the simulations in this work, we take the diffusivity of $\mathrm{H}^{+}$from the low temperature results of Gorelkinskii and Nevinnyi, ${ }^{71}$ while a conservative diffusivity of $\mathrm{H}^{0}$ is taken to be that determined by VWW. ${ }^{64}$ Finally, the diffusivity of $\mathrm{H}^{-}$ is taken from the work of Johnson and Herring. ${ }^{69}$ The diffusivities used are thus as follows:

$$
\begin{gathered}
D_{H^{+}}=4.24 \times 10^{-4} \exp \left(\frac{-0.43}{k T}\right), \\
D_{H^{0}}=9.67 \times 10^{-3} \exp \left(\frac{-0.48}{k T}\right), \\
D_{H^{-}}=1.3 \times 10^{-2} \exp \left(\frac{-0.7}{k T}\right) .
\end{gathered}
$$

As a consequence of its high charge to mass ratio, the motion of hydrogen in silicon is also strongly affected by electric fields. Several authors ${ }^{69,73}$ have shown that an applied bias across a Schottky junction can sweep hydrogen, and internal electric fields due to doping profiles within the silicon can also have a significant influence. ${ }^{37}$ Mobilities $(\mu)$ used in our work are calculated via a simple Einstein relation to the diffusivity

$$
\mu_{X}=\frac{D_{X}}{k T} .
$$

Despite having the largest activation energy, these relations predict that the diffusivity of $\mathrm{H}^{-}$at $400{ }^{\circ} \mathrm{C}$ will be $7.30 \times 10^{-6} \mathrm{~cm}^{2} \mathrm{~s}^{-1}$, approximately three times larger than that of $\mathrm{H}^{0}$, while $\mathrm{H}^{+}$has an even lower diffusivity of $2.55 \times 10^{-7} \mathrm{~cm}^{2} \mathrm{~s}^{-1}$. This apparent discrepancy is likely a result of extrapolation of the diffusivities from very different temperatures. It should be noted that $D_{H^{-}}$has very little impact upon the results of simulations in this work in and of itself, as strong electric fields are present in all regions where $\mathrm{H}^{-}$exists in large concentrations, and hence profiles are determined largely by the ratio of drift and diffusion fluxes of $\mathrm{H}^{-}$.

In contrast, the impact of different values of $D_{H^{0}}$ requires further consideration. In these simulations, no distinction is made between $\mathrm{H}^{0}$ at the bond centred and tetrahedral sites $\left(H_{B C}^{0}\right.$ and $\left.H_{T}^{0}\right)$, and a single diffusivity is used for both species. In order to examine the effect this has upon the results, simulations will be presented using both the conservative value in (8) and the highest values reported. ${ }^{30}$

\section{Interaction with impurities}

Another important effect is the interaction of the various hydrogen charge states with defects and impurities. One of the most studied traps for interactions with interstitial hydrogen are dopant impurities. Hydrogen has been observed to bond to both shallow acceptors and donors in silicon. ${ }^{26,27,59}$ It is generally agreed that these bonds form due to the interaction of the dopant ion with the opposite charge state of hydrogen i.e.,

$$
\begin{aligned}
& \mathrm{B}^{-}+\mathrm{H}^{+} \rightarrow \mathrm{HB}, \\
& \mathrm{P}^{+}+\mathrm{H}^{-} \rightarrow \mathrm{HP} .
\end{aligned}
$$

Hydrogen-dopant pairs have relatively low binding energies, estimated between 0.7 and $0.85 \mathrm{eV}$ (Refs. 28, 74, and 75) for $\mathrm{HB}$ and a wider spread of 0.5 to $0.71 \mathrm{eV}$ for HP. ${ }^{63,69,76}$ At dopant concentrations up to $1 \times 10^{16} \mathrm{~cm}^{-3}$, these pairs have been observed to dissociate rapidly with processing above $200^{\circ} \mathrm{C}$. HP pairs have often been referred to as dissociating much more readily than $\mathrm{HB}$; however, this possibly owes more to the asymmetry in the hydrogen charge states rather than any great difference in binding energies. ${ }^{63}$ They have also been observed to show markedly increased rates of dissociation in the presence of minority carrier injection, from either illumination ${ }^{28,77}$ or applied bias. It is not clear how much of this is due to carriers playing a role in dissociation and how much from alterations in the charge states of interstitial hydrogen. ${ }^{28,63,77}$ Interaction with excess minority carriers may be safely ignored in this equilibrium model; however, moving to a non-equilibrium model will require a more involved set of equations. 
For this paper, we use the following rates of trapping and de-trapping at dopant impurities from Refs. 63, 66, and 70 :

$$
\begin{gathered}
\frac{d[H B]}{d t}=C_{B 1}\left[H^{+}\right]\left[B^{-}\right]-2.8 \times 10^{14} \exp \left(\frac{-1.28}{k T}\right)[H B], \\
\frac{d[H P]}{d t}=C_{P 1}\left[H^{-}\right]\left[P^{+}\right]-1 \times 10^{13} \exp \left(\frac{-1.18}{k T}\right)[H P],
\end{gathered}
$$

where

$$
\begin{gathered}
C_{B 1}=\frac{D_{H^{+}} q^{2}}{\varepsilon_{S i} k T}, \\
C_{P 1}=\frac{D_{H^{-}} q^{2}}{\varepsilon_{S i} k T} .
\end{gathered}
$$

$\varepsilon_{\mathrm{Si}}$ is the permittivity of silicon in $\mathrm{F} / \mathrm{cm}$. It should be noted that the trapping of hydrogen at phosphorus is not well understood at temperatures above $200^{\circ} \mathrm{C}$, and may have a noticeable impact upon the results. Given Eq. (8) and (10), it is possible to calculate that at the temperatures used in this work, we actually obtain a higher equilibrium ratio of $[\mathrm{HP}]:\left[\mathrm{H}^{-}\right]$than for $[\mathrm{HB}]:\left[\mathrm{H}^{+}\right]$, which is contrary to expectations.

It has also been demonstrated that hydrogen can bond to metallic impurities and crystallographic defects in silicon, including dislocations, ${ }^{78,79}$ self-interstitials, ${ }^{80,81}$ and vacancies. ${ }^{82,83}$ Furthermore, interstitial hydrogen is also known to interact strongly with itself and other forms of hydrogen to form hydrogen dimers, including interstitial hydrogen molecules, or extended defects. ${ }^{84-86}$ Recent work by Voronkov and Falster has identified at least three forms of the hydrogen dimer within silicon at low temperatures, ${ }^{29}$ which are predicted to dominate over atomic hydrogen at temperatures up to $650^{\circ} \mathrm{C}$ under equilibrium conditions. ${ }^{29,37}$

Extended defects typically nucleate at a dislocation or vacancy, ${ }^{87}$ and some "platelets" can extend across the entire wafer along the (111) or (100) planes. These platelets form much more readily in n-type silicon than in $\mathrm{p}$-type ${ }^{88}$ and it has been suggested that nucleation requires both $\mathrm{H}^{-}$and $\mathrm{H}^{+}{ }^{89}$ Platelet nucleation is reported to be suppressed with processing at temperatures above $350{ }^{\circ} \mathrm{C},{ }^{90}$ although platelets already nucleated at lower temperatures can grow rapidly when exposed to temperatures in this range.

The picture is further complicated in multicrystalline silicon due to the interaction of hydrogen with grain boundaries. It has been suggested that the diffusion of hydrogen can be enhanced at grain boundaries, ${ }^{91}$ and also that grain boundaries act as traps for hydrogen, reducing its ability to diffuse into the silicon. ${ }^{92-94}$ From other reports in the literature, it is plausible to suggest that the number of defect states at the surface plays a significant role in the in-diffusion of hydrogen. ${ }^{42,43,92}$

In these simulations, both the rapidly dissociating dimer, tentatively identified as interstitial molecular hydrogen, and the slow-forming dimer $\left(\mathrm{H}_{2 \mathrm{~A}}\right.$ and $\mathrm{H}_{2 \mathrm{C}}$, respectively, as defined by Ref. 29) are considered, with trapping and detrapping rates given by

$$
\frac{d\left[H_{2 A}\right]}{d t}=1.3 \times 10^{-6} \exp \left(\frac{-1.3}{k T}\right)\left(\left[H^{+}\right]\left[H^{0}\right] / k_{H_{2} A}-p\left[H_{2 A}\right]\right),
$$

$$
\frac{d\left[H_{2 C}\right]}{d t}=5.5 \times 10^{11} \exp \left(\frac{-1.5}{k T}\right)\left(\frac{[H B]^{2}}{[B]}-\frac{[H B]\left[H_{2 C}\right] p^{2}}{5.25 \times 10^{51}}\right),
$$

where $k_{\mathrm{H}_{2} \mathrm{~A}}$ is defined by the ratio of hydrogen dimers to HB. The diffusion of $\mathrm{H}_{2 \mathrm{~A}}$ dimers is also included, with a diffusivity of Ref. 29

$$
D_{H_{2 A}}=1 \times 10^{-3} \exp \left(\frac{-0.8}{k T}\right) .
$$

While other dimers or hydrogen complexes undoubtedly play a significant role as traps for interstitial hydrogen, these are likely to vary with material properties and are not considered in these simulations. A notable omission in the current model is the interaction of interstitials and vacancies with hydrogen dimers. It has been reported that these are likely to increase the dissociation of dimers ${ }^{95}$ beyond that assumed in this work. In particular, for the case of diffusion in phosphorous emitters, the high vacancy concentrations may act to reduce the concentration of hydrogen dimers. ${ }^{95,96}$

\section{MODELLING HYDROGEN TRANSPORT AT MODERATE TEMPERATURES}

In all simulations, interstitial hydrogen will be assumed to exist in local equilibrium between its various charge states at all times. This is justified by noting that in solar cells the self-ionization reaction

$$
H^{0} \rightarrow H^{+}+e^{-},
$$

provides a reasonable measure of the timeframe required for hydrogen to reach an equilibrium between its charge states at a given location. Given that both $\mathrm{H}^{+}$and $\mathrm{H}^{0}$ have the same minimum energy location in the silicon crystal lattice, the activation energy may be expected to be merely the difference between the donor level and the edge of the conduction band, namely, $0.16 \mathrm{eV}$. This has been shown to fit experimental data at $-200^{\circ} \mathrm{C}$ with an exponential pre-factor of $7.9 \times 10^{12} \mathrm{~s}^{-1} .^{72}$ This results in a self-ionization rate of $1.6 \times 10^{10} \mathrm{~s}^{-1}$ at room temperature and $5 \times 10^{11} \mathrm{~s}^{-1}$ for simulations at $673 \mathrm{~K}$. This is at least eight orders of magnitude greater than the rates for all other processes considered in this model, including diffusion and trapping at impurities.

The model is based on a 2nd order backwards difference formula evaluated using a single Newton-Raphson iteration and a tolerance of $0.1 \%$. The full model and further details of the applied solving procedures can be found in Appendix A.

\section{THE INTERACTION OF HYDROGEN WITH PHOSPHOROUS EMITTERS}

The first scenario of interest is the migration of hydrogen across a shallow but heavily phosphorous doped emitter. This is of particular importance for silicon photovoltaics, as 


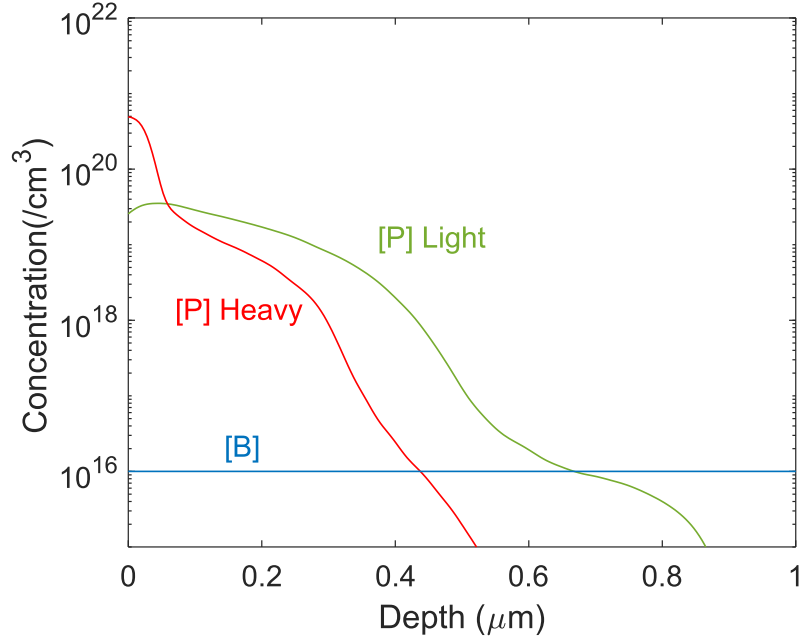

FIG. 2. Dopant concentrations in the first $\mu \mathrm{m}$ of structures used in our simulations, as reported in Ref. 99. The "heavy" profile has a sheet resistance of $79 \Omega /$ sq. while the "light" profile has a sheet resistance of $89 \Omega /$ sq.

standard cell structures use a heavily doped phosphorous emitter on the front surface immediately beneath the dielectric layer, which is the main source of hydrogen for bulk passivation. To reach the bulk, the hydrogen must therefore diffuse through the heavily doped emitter region.

Several authors have reported significant retardation of hydrogen transport into silicon samples at low temperatures in the presence of a thin $\mathrm{n}^{+}$emitter. ${ }^{73,97}$ The transport of hydrogen across lightly doped emitters has also been observed to depend heavily upon temperature, with orders of magnitude changes in hydrogen penetration going from $480{ }^{\circ} \mathrm{C}$ to $610^{\circ} \mathrm{C}$ in thin crystalline silicon devices. ${ }^{36,98}$

We carry out simulations for two different active phosphorous profiles on a p-type $1 \times 10^{16} \mathrm{~cm}^{-3}$ boron doped substrate as reported for a recent study. ${ }^{99}$ These profiles are pictured in Fig. 2. The first profile was chosen to be typical of modern screen-printed solar cells while the second represents a "light" modified profile using a hightemperature oxidation step. The light diffusion has a much lower peak doping concentration at the surface and penetrates further into the silicon. Despite this, the two profiles do not have markedly different sheet resistances.

Figure 3 presents the results of simulations carried out at a temperature of $300{ }^{\circ} \mathrm{C}$ using the heavy diffusion profile. It is clear that the vast majority of hydrogen is initially trapped within the phosphorous doped emitter, with a drop in concentration of more than five orders of magnitude between the surface concentration and that at $1 \mu \mathrm{m}$ depth for times up to $160 \mathrm{~s}$. It is not until the hydrogen concentration in the emitter approaches the doping concentration that this decreases to a mere three orders of magnitude. A comparison with the profile obtained after just $10 \mathrm{~s}$ with no emitter present demonstrates how greatly the transport of hydrogen is impeded by the presence of a phosphorus emitter.

Part of the reason for this precipitous decrease may be found in Fig. 3(d), which depicts the concentrations of $\mathrm{H}^{+}$, $\mathrm{H}^{0}$, and $\mathrm{H}^{-}$after $80 \mathrm{~s}$. A clear cross-over point is visible at approximately $400 \mathrm{~nm}$ depth. This is not the location of the metallurgical junction but rather the point at which the Fermi level in the silicon is such that the dominant form of interstitial hydrogen switches from $\mathrm{H}^{-}$to $\mathrm{H}^{+}$. The electric field at this point then sweeps $\mathrm{H}^{+}$further into the silicon, while $\mathrm{H}^{-}$ is repelled towards the surface, thus creating a local minima in the hydrogen concentration. Beyond this point, there is no significant barrier to hydrogen transport into the silicon bulk. However, in the region between the surface and this inflexion point, the dominant $\mathrm{H}^{-}$is subject to a strong electric field opposing in-diffusion. This results in a steep concentration gradient.

The steep concentration gradient is exacerbated by the effects visible in Fig. 3(c). In particular, the trapping of hydrogen by phosphorous leads to very large concentrations of hydrogen within the emitter region. Indeed, significant

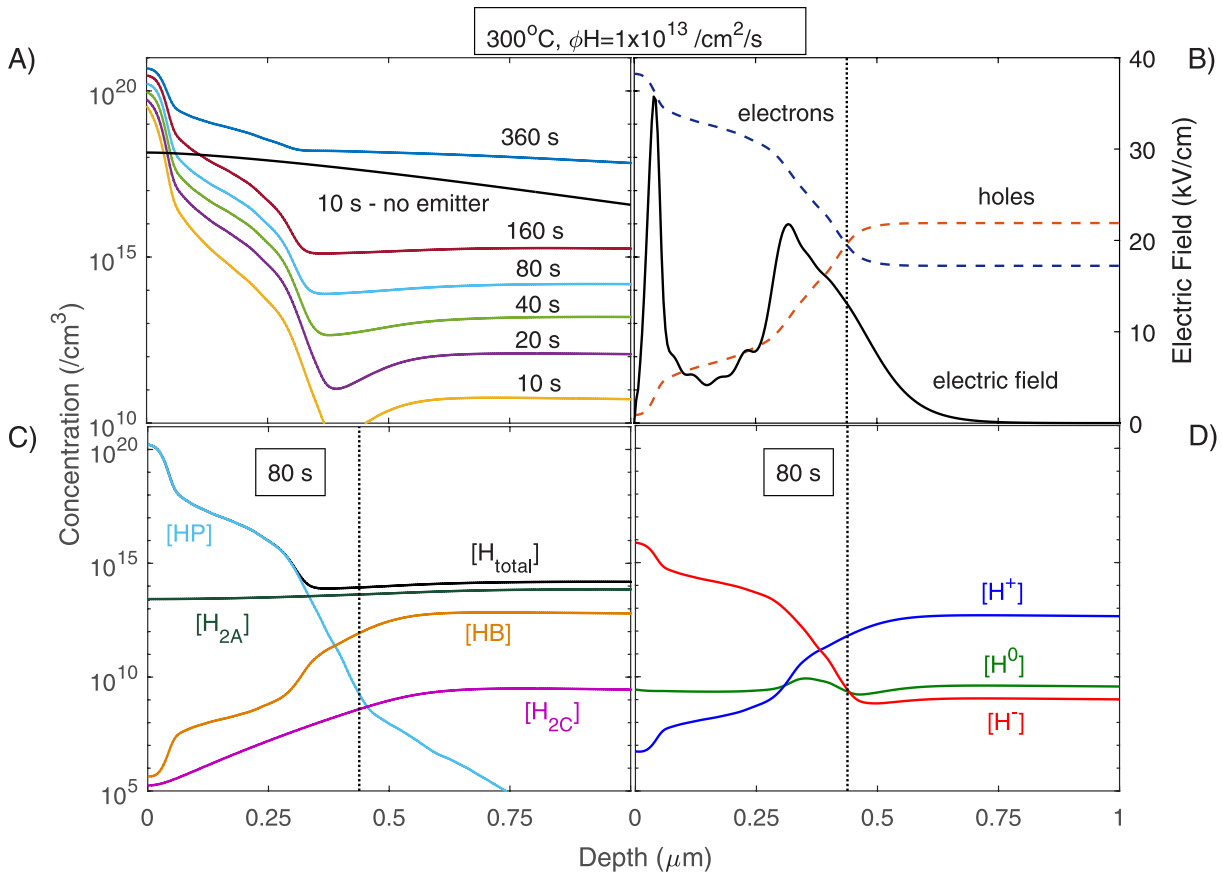

FIG. 3. Simulations at $300^{\circ} \mathrm{C}$ in the $\mathrm{Si}$ wafer with the heavy phosphorus profile of Fig. 2 and an influx of hydrogen of $1 \times 10^{13} \mathrm{~cm}^{-2} \mathrm{~s}^{-1}$. (a) Total hydrogen concentration, for the indicated simulation times and, for comparison, a simulation for a $10 \mathrm{~s}$ process without any emitter (dashed line). (b) Electric field and carrier concentrations after 80 s. (c) Total hydrogen concentration and hydrogen complex concentrations including hydrogen dimers and hydrogen-dopant pairs at a simulation time of $80 \mathrm{~s}$. (d) Concentrations of $\mathrm{H}^{+}$, $\mathrm{H}^{0}$, and $\mathrm{H}^{-}$after $80 \mathrm{~s}$. Vertical, dotted line at equal carrier densities. 

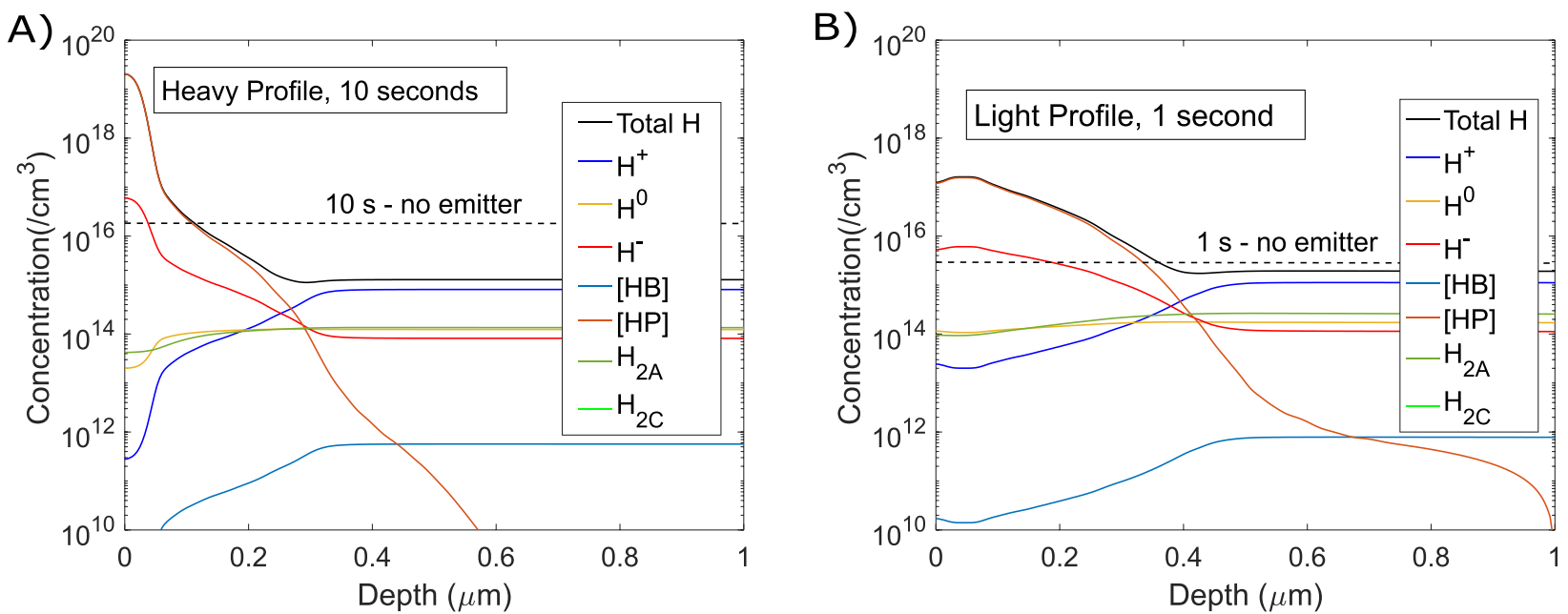

FIG. 4. Simulated concentrations of interstitial hydrogen, hydrogen dimers and hydrogen-dopant pairs for an influx of hydrogen of $1 \times 10^{13} \mathrm{~cm}^{-2} \mathrm{~s}^{-1}$ for $(\mathrm{a})$ the "heavy" phosphorus diffusion profile for $10 \mathrm{~s}$ at $700{ }^{\circ} \mathrm{C}$ and (b) the "light" phosphorus diffusion profile for $1 \mathrm{~s}$ at $700{ }^{\circ} \mathrm{C}$. In both cases, the concentration of $\mathrm{H}_{2 \mathrm{C}}$ is well below the range displayed.

transport of hydrogen into the bulk only occurs when the vast majority of phosphorous in the emitter has been deactivated by hydrogen. This reduces both the chances of further trapping and the electric fields in that region. It can also be seen that at these temperatures, there is an expectation that the majority of the hydrogen in the bulk will form dimers, reducing its ability to passivate other defects.

It is entirely expected that the diffusion of hydrogen across an n-type emitter will increase with temperature. However, the simulations presented in Fig. 3 clearly elucidate the reasons for this behaviour. The dominant effects are a reduction in trapping of hydrogen at phosphorous in the emitter and an increase in the fraction of interstitial hydrogen in the positive and neutral charge states in this region. In particular, the cross-over point moves towards the surface as the increase in the intrinsic carrier density shifts the Fermi level towards mid-gap. The increased diffusivity of hydrogen and the increase in the ratio of interstitials to dimers play relatively minor roles in the increased flux of hydrogen across the emitter, while the increase in the ratio of diffusivity to mobility is largely counterbalanced by an increased electric field in the near surface region. Although the increase in hydrogen transport across an emitter is clearly heavily temperature dependent, the simulations in Fig. 4 predict that it is at least as dramatically influenced by the emitter doping profile. A similar amount of hydrogen is observed on the p-type side of the diode in $1 \mathrm{~s}$ for simulations using the "light" profile as is observed for $10 \mathrm{~s}$ simulations with the "heavy" emitter profile. The $10 \Omega /$ sq. difference in sheet resistance (and in total active phosphorous) is not anywhere near as significant as this change in hydrogen transport.

A comparison of Figs. 4(a) and 4(b) leads to a clear explanation for this difference at $700{ }^{\circ} \mathrm{C}$. The first $50 \mathrm{~nm}$ of the heavy profile has active phosphorous concentrations above $1 \times 10^{20}$ atoms $/ \mathrm{cm}^{3}$, an order of magnitude higher than the peak doping concentration in the light profile. Due to this higher dopant concentration, both trapping of hydrogen and the electric field at the edge of this region are greatly enhanced. These simulations would therefore predict that it is the peak doping concentration that is most critical for hydrogen transport, not the sheet resistance or the total phosphorous dose in the emitter.

Figure 5 presents the concentration of hydrogen on the bulk side of the emitter for both diffusion profiles at temperatures of 300,500 , and $700{ }^{\circ} \mathrm{C}$. Interestingly, the effect of the emitter doping profile is more pronounced with increasing temperature, leading to the expectation that it would have a significant impact at traditional firing temperatures in excess of $800^{\circ} \mathrm{C}$. This is supported by results in the literature, ${ }^{33-35}$ where an increase in bulk excess carrier lifetime (indicative of superior hydrogen passivation) was observed after firing when a lighter emitter diffusion was employed.

The explanation of this behaviour is relatively straightforward with our simulations; at the lowest temperatures, nearly all phosphorous needs to be de-activated for significant hydrogen transport to occur. Therefore, the relative importance of peak doping vs. total phosphorous dose is decreased, although it remains a significant factor. The actual situation will be more complicated due to incomplete ionization of phosphorous dopants, ${ }^{100}$ clustering of phosphorous atoms in silicon, ${ }^{101}$ and interactions with vacancies resulting from emitter formation. ${ }^{96,102}$

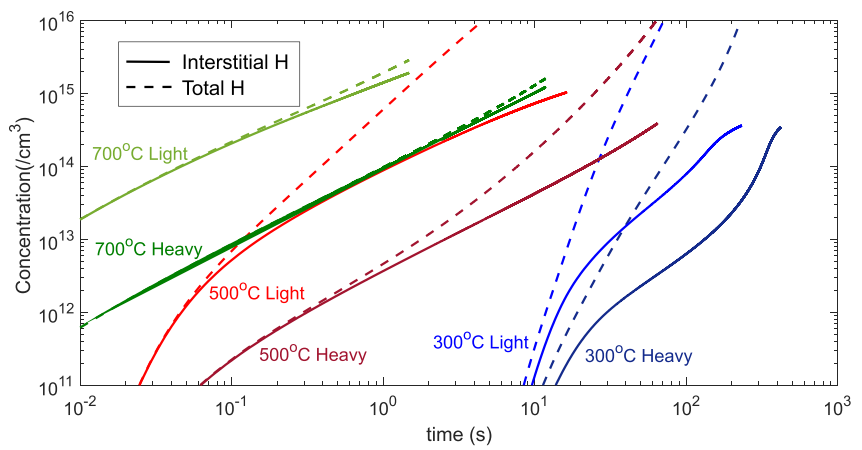

FIG. 5. Simulated concentrations of total and interstitial hydrogen beyond the "heavy" and "light" phosphorus profile (of Fig. 2) in the p-type wafer at a depth of $1 \mu \mathrm{m}$, as a function of time, at 300,500 , and $700^{\circ} \mathrm{C}$ with an influx of hydrogen of $1 \times 10^{13} \mathrm{~cm}^{-2} \mathrm{~s}^{-1}$. 

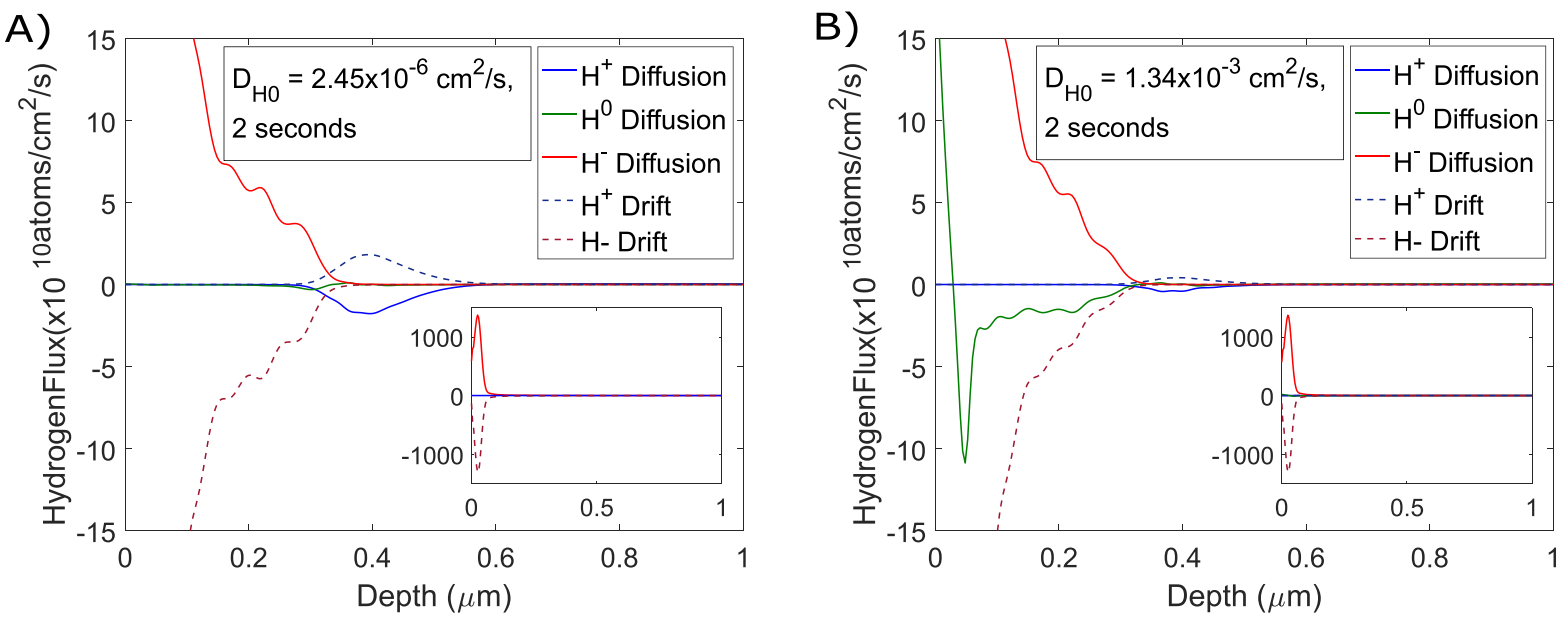

FIG. 6. Hydrogen fluxes due to drift and diffusion of $\mathrm{H}^{+}, \mathrm{H}^{0}$, and $\mathrm{H}^{-}$in the first $1 \mu \mathrm{m}$ of structures simulated at $400{ }^{\circ} \mathrm{C}$ for $2 \mathrm{~s}$ with an influx of hydrogen of $1 \times 10^{13} \mathrm{~cm}^{-2} \mathrm{~s}^{-1}$ (a) for a $\mathrm{H}^{0}$ diffusivity of $2.45 \times 10^{-6} \mathrm{~cm}^{2} / \mathrm{s}$ used in this work [Eq. (8)] and (b) for the much higher $\mathrm{H}^{0}$ diffusivity of $1.34 \times 10^{-3} \mathrm{~cm}^{2} / \mathrm{s} \mathrm{given}^{2}$ by Eq. (15).

It has been suggested ${ }^{29}$ that the primary means of hydrogen transport across n-type emitters at low temperatures is via the diffusion of $\mathrm{H}^{0}$. The simulations in this work do not support that conclusion at temperatures above $300^{\circ} \mathrm{C}$. However, as discussed in Sec. III B, the value for the diffusivity of $\mathrm{H}^{0}$ is the subject of some debate. In Fig. 6, the hydrogen fluxes for simulations carried out with the original value for $D_{H^{0}}$, given in Eq. (8), are compared with simulations using the much higher value proposed by Refs. 30 and 72

$$
D_{H^{0}}=0.015 \times \exp \left(\frac{-0.14}{k T}\right) .
$$

Somewhat counter-intuitively, an increase in the diffusivity of $\mathrm{H}^{0}$ by nearly three orders of magnitude actually decreased the flux of hydrogen across the emitter. This is due to the $\mathrm{H}^{0}$ concentration actually increasing away from the surface, which is in turn due to the change in the Fermi level. Nonetheless, the dominant fluxes remained the drift and diffusion of the charged species, $\mathrm{H}^{-}$near the surface and
$\mathrm{H}^{+}$across the depletion region. It is therefore concluded that at temperatures above $300^{\circ} \mathrm{C}$, hydrogen transport across ntype emitters occurs primarily via the motion of the charged species, and that the generation of $\mathrm{H}^{+}$on the n-type side of the junction is critical for significant incorporation of hydrogen to the p-type bulk.

\section{THE INTERACTION OF HYDROGEN WITH BORON EMITTERS}

Another important conclusion of these simulations is that while heavily doped n-type emitters present a significant challenge for hydrogen in-diffusion at low temperatures, heavily doped p-type emitters on n-type substrates are more difficult still.

In Fig. 7, the $500{ }^{\circ} \mathrm{C}$ simulations for the light phosphorus emitter are compared with a recently reported boron emitter, ${ }^{103}$ with a similar peak doping concentration. The first point of interest is that although the total boron dose in the emitter in Fig. 7(a) is higher than in the phosphorus profile,
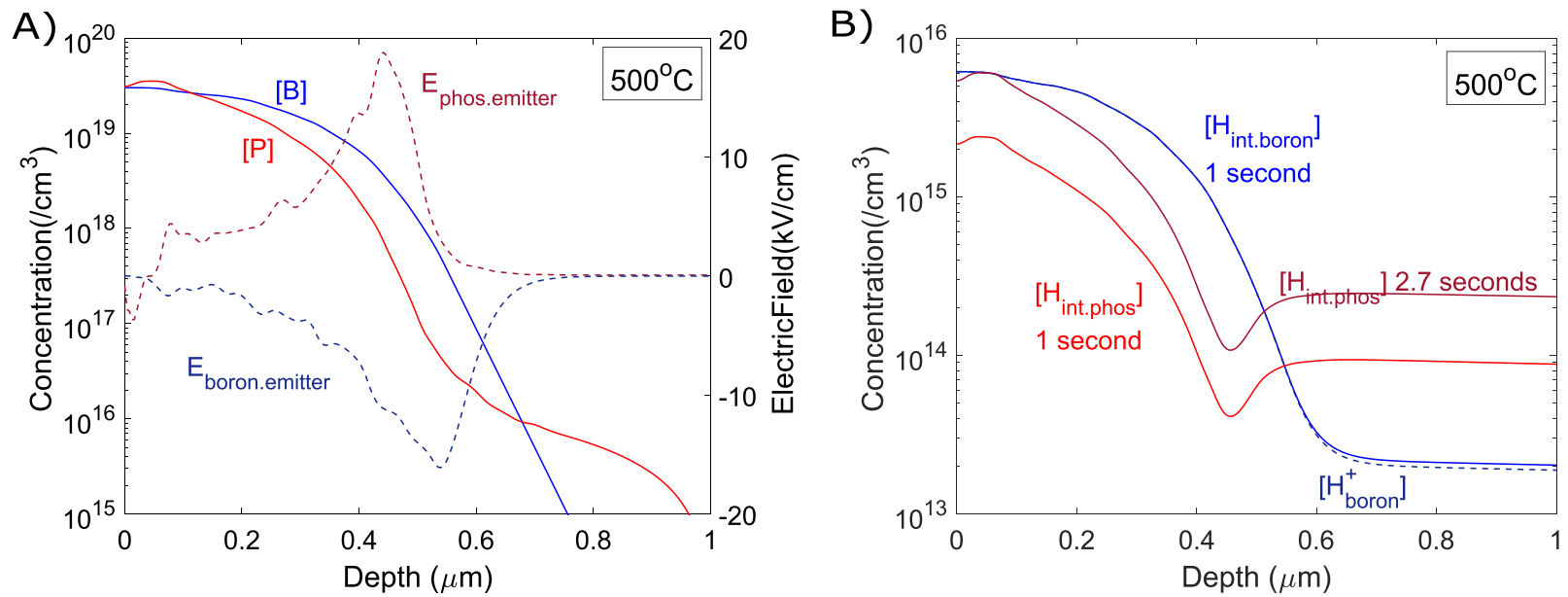

FIG. 7. (a) Active dopant profiles for the boron emitter (blue lines) used in this work, compared with the light phosphorus diffusion (red lines). The resulting electric fields for both profiles at $500^{\circ} \mathrm{C}$ with an influx of hydrogen of $1 \times 10^{13} \mathrm{~cm}^{-2} \mathrm{~s}^{-1}$ are plotted on the right axis. (b) Simulated interstitial hydrogen concentrations at $500{ }^{\circ} \mathrm{C}$ for the boron emitter structure after $1 \mathrm{~s}$ (solid blue line), phosphorus diffusion after $1 \mathrm{~s}$ (red line) and $2.7 \mathrm{~s}$ (dark red line). The $\mathrm{H}^{+}$concentration for the boron emitter structure is depicted with a dashed blue line that largely coincides with the interstitial hydrogen concentration. 
due to the lower mobility of holes, the sheet resistance is $\sim 110 \Omega /$ sq. c.f. $89 \Omega /$ sq. for the phosphorus emitter. For similar sheet resistances, still more boron will be required, which introduces more traps for hydrogen within the emitter. Comparing Figs. 7(a) and 7(b), it may be observed that despite the similar electric field strengths across the emitter, the transport of interstitial hydrogen is significantly lower for the boron emitter. This is due to the fact that the hydrogen charge state cross-over point will always occur on the n-type side of the metallurgical junction. The transport of hydrogen across a boron emitter will therefore be opposed by the electric field over its entire dimension.

These results are also affected by the trapping of hydrogen at phosphorus and boron in their respective emitters. As mentioned in Sec. III C, the experimentally observed values used in our simulations predict a stronger trapping of $\mathrm{H}^{-}$as $\mathrm{HP}$ than $\mathrm{H}^{+}$as $\mathrm{HB}$; however, most reports in the literature would expect the opposite to be true. ${ }^{37,65,104}$ While there is a lack of reliable data on hydrogen trapping at HP, should it be weaker or comparable to trapping at HB, this would exacerbate the reduction in hydrogen transport across a boron emitter compared with a phosphorus emitter.

The difference between transport across phosphorous and boron doped emitters is likely to become even more pronounced under non-equilibrium conditions. Using the capture cross-sections in the current model, any increase in the hole concentration in an n-type emitter will act to increase the concentration of $\mathrm{H}^{+}$in this region. In contrast, increasing the electron concentration in a heavily boron doped region will lead to a much smaller increase in the $\mathrm{H}^{-}$concentration.

\section{IMPLICATIONS FOR DIFFERENT CELL ARCHITECTURES}

The simulated dependence of hydrogen introduction on the phosphorous emitter profile has important implications for screen-printed solar cell structures. The emitter peak doping concentrations in these cells have been decreasing for a decade, ${ }^{105}$ largely stimulated by reducing the inactive phosphorus clusters, ${ }^{106}$ which act as recombination sites, ${ }^{107}$ and enabled by improved silver pastes. ${ }^{108,109}$ It might therefore be expected that modern solar cells are experiencing elevated bulk concentrations of hydrogen in the base region.

Another observation from these simulations relates to differences in the behaviour of hydrogen at these temperatures in standard, full-area aluminium back surface field cells (Al-BSF) compared with Passivated Emitter Rear Cells (PERC), which have only localized BSF's. ${ }^{110,111}$ It is expected that the PERC structure will contain much higher concentrations of hydrogen within the silicon bulk for the following reasons.

The primary difference is the presence of an effective hydrogen source, most commonly in the form of an $\mathrm{AlO}_{\mathrm{x}}: \mathrm{H} /$ $\mathrm{SiN}_{\mathrm{x}}: \mathrm{H}$ stack, ${ }^{112}$ at the rear of the PERC cell, as opposed to an effective hydrogen sink in the form of a full-area $\mathrm{Al}: \mathrm{Si}$ alloyed region. Hydrogen may be introduced into a PERC cell from the rear-passivating layer with no significant diffusion barrier beyond that encountered in the bulk silicon. The presence of another hydrogen source at the front surface, albeit one screened by a phosphorous emitter, means that at the very worst, net out-diffusion from the front surface is unlikely. It might therefore be expected that significant concentrations of hydrogen might be built up in these devices as a result of processes at temperatures from 200 to $600^{\circ} \mathrm{C}$, potentially including cooling from the co-firing process.

In contrast, for hydrogen to be introduced into full-area Al-BSF cells, it must be released from a $\mathrm{SiN}_{\mathrm{x}}: \mathrm{H}$ layer on the front surface and be transported across a heavily doped phosphorous emitter. Much of hydrogen within the bulk that manages to diffuse to the rear surface will also segregate to the $\mathrm{Al}: \mathrm{Si}$ alloyed region and therefore it is predicted that a much less significant build-up of hydrogen will occur in standard cells with processing below $873 \mathrm{~K}$.

As a result, processes related to hydrogen are expected to be much more pronounced in PERC structures. This may be a significant benefit in passivating defects in multicrystalline silicon ${ }^{1,78}$ and accelerating the permanent deactivation of the boron-oxygen defect. ${ }^{113,114}$ An increased effectiveness of boron-oxygen treatment processes on PERC cells has already been reported, although it is difficult to separate any effects of increased hydrogen concentration from those due to increased carrier concentrations in PERC cells under illumination when compared with full-area Al-BSF devices. ${ }^{10}$ However, there are also some potentially deleterious effects linked to these elevated hydrogen concentrations, including the formation of hydrogen-related defects. ${ }^{19,20}$

A further implication of our simulations concerns passivated emitter totally diffused (PERT) cells on n-type wafers. Because no BSF can be formed with $\mathrm{Al}$ contacts, the difficulties of local phosphorus diffusions are avoided by having a full-area phosphorus diffusion with the hope to require only a mediocre rear passivation quality. Hence, both the front (and rear) surfaces receive a full-area boron (and phosphorus) diffusion, so it is difficult to incorporate $\mathrm{H}$ into the base region. The simplicity of having solely full-area diffusions may be offset by difficulties in improving excess carrier lifetime, as particularly the passivation of shallow, thermally generated defects is important in such cells. The carrier lifetime is often lower at the end of fabrication compared with the initial lifetime in the wafer. ${ }^{115}$

Interdigitated back contact (IBC) cells on n-type wafers usually have a very light and shallow phosphorus diffusion to form a front surface field (FSF), if at all, and therefore can be flooded with hydrogen at rather low temperatures.

\section{RE-DISTRIBUTION OF HYDROGEN ACROSS PHOSPHOROUS EMITTERS}

While the mechanism by which hydrogen might be introduced to the bulk of solar cell structures during firing processes is of most interest, it is also instructive to examine how hydrogen might be redistributed during subsequent thermal processes. In particular, a number of post-firing thermal processes have been proposed to deal with issues such as degradation in mono- and multi- crystalline silicon, ${ }^{13,14,16}$ and to perform low temperature gettering. ${ }^{11,116}$

The simulations in Fig. 8 assume a uniform initial hydrogen distribution throughout the material, and zero 


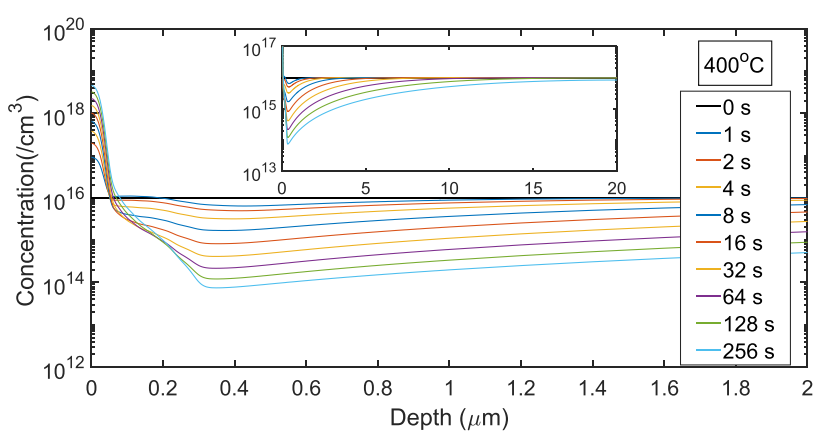

FIG. 8. Depth profile of total hydrogen concentration with no surface flux when annealed at $400{ }^{\circ} \mathrm{C}$ with the heavy phosphorus doping profile. The initial hydrogen concentration was uniform, at $1 \times 10^{16}$ atoms $/ \mathrm{cm}^{3}$.

out-diffusion from the silicon surface. While this scenario is again somewhat simplistic, it does allow examination of the general behaviour of hydrogen during post-firing processes. In line with previous work, under similar conditions, it is assumed that all hydrogen initially begins as $\mathrm{H}_{2 \mathrm{~A}}$ dimers.

Compared with the simulations on in-diffusion in Sec. V, it is unsurprising that hydrogen in the emitter is swept towards the surface by the electric field, and largely exists bound to phosphorous at these sites. Perhaps less expected is the extent to which hydrogen from the bulk p-type material migrates to the emitter region. In a matter of minutes at $400{ }^{\circ} \mathrm{C}$ most of the hydrogen in the first $20 \mu \mathrm{m}$ of the material is simulated to move to the emitter. This extraction would be even more rapid were it not for most of the hydrogen in the bulk existing as dimers at this temperature. Once more, this is largely driven by the presence of the cross-over point, creating a strong local minimum in hydrogen concentration.

For these samples, the assumption of uniform distribution is more accurate than might be supposed. As the primary region of interest lies beneath the metal contacts, which are rapidly fired through the $\mathrm{SiN}_{\mathrm{x}}: \mathrm{H}$ layer at with 1 to $2 \mathrm{~s}$ at high temperature, there is likely less in-diffusion of hydrogen from the front surface. In which case, hydrogen from the rear dielectric layers and lateral diffusion of hydrogen in the bulk will likely lead to a more uniform depth distribution than for regions without metal contacts.

Experimental evidence for the build-up of hydrogen at solar cell surfaces may be found in recent observations of an increase in front contact resistance when cells are thermally processed after firing of the metal contacts. ${ }^{14,117}$ Figure 9 depicts this change for industrial multicrystalline PERC cells annealed at $353{ }^{\circ} \mathrm{C}$, which follows a similar behaviour to the simulated build-up of hydrogen at the front surface, albeit with a much larger time constant. While some authors have attributed this to a thickening of the glass layer at the $\mathrm{Ag} / \mathrm{Si}$ interface, ${ }^{117}$ a recent study observed a high degree of instability in the contact resistance under an applied bias at room temperature. ${ }^{24}$ Furthermore, the behaviour under bias is consistent with the motion of $\mathrm{H}^{-}$, the dominant form of mobile hydrogen in heavily doped n-type materials at this temperature. It is not yet clear whether the hydrogen is located at the interface itself or in the underlying silicon.

It is possible that this redistribution of hydrogen will also affect the hydrogen and defect activity within the bulk.

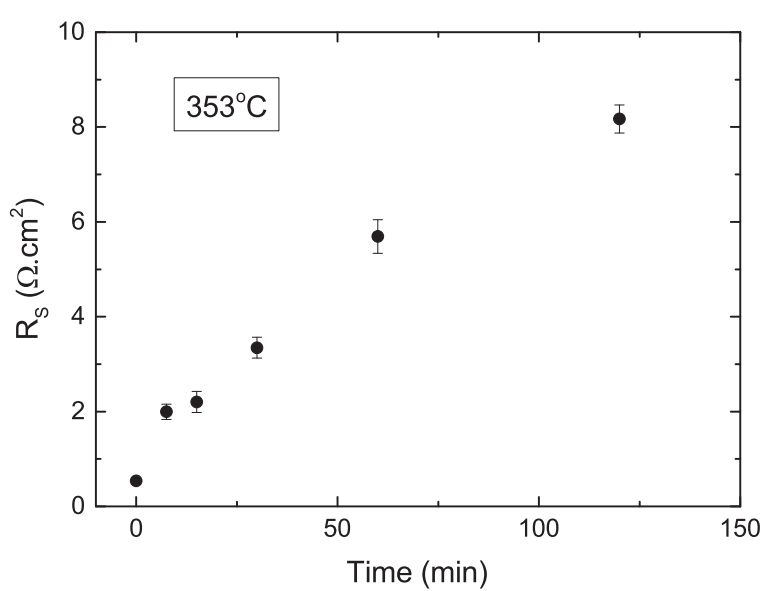

FIG. 9. Series resistance as a function of annealing time at $353{ }^{\circ} \mathrm{C}$ for industrial p-type multicrystalline PERC solar cells.

In particular, if the temperature is high enough to lead to a significant dissociation of hydrogen-defect complexes, the reduction in total hydrogen concentration in the bulk may lead to an increase in recombination active defects and hence a reduction in bulk lifetime. Conversely, several recent papers have identified hydrogen as potentially involved in bulk lifetime degradation of silicon materials, ${ }^{13,16}$ and as such, it may be that reducing the concentration of hydrogen in the bulk that is not passivating deep level defects will reduce the rate and extent of degradation and increase the stable bulk lifetime of the silicon material. This could potentially explain why these post-firing thermal processes appear to be effective at reducing degradation effects.

\section{CONCLUSION}

The use of hydrogen to passivate defects in silicon is essential in order to achieve high efficiencies on materials containing significant impurity concentrations. If hydrogen passivation techniques are to be effectively deployed at temperatures below those currently used for metal co-firing, there are a number of challenges that need to be met. An effective source of atomic hydrogen is required to introduce hydrogen into the silicon; however, this is in many ways the easiest hurdle to overcome. More challenging is to ensure that hydrogen is distributed throughout the silicon bulk in such a way that it passivates recombination centres.

To this end, our simulations lead to three primary conclusions. Firstly, as expected, the transport of hydrogen across an n-type emitter is heavily dependent upon temperature. Secondly, the transport of hydrogen under equilibrium conditions is largely driven by the charged species of hydrogen, with the switch from a dominance of $\mathrm{H}^{-}$to $\mathrm{H}^{+}$within the emitter region critical to significant transport across the junction. Finally, the doping profile within the emitter plays a key role, in particular, the peak doping concentration has a large influence on how much hydrogen reaches the silicon bulk.

It was observed in our simulations that during postfiring anneal, hydrogen will preferentially migrate to the surface of a phosphorous doped emitter, drawing hydrogen out 
of the p-type bulk. This may play a role in several effects observed during post-firing anneals.

While the simulations in this work can illuminate general behaviours, there are several open questions. Comparison of the model with further experiments may well lead to improved values for many of the input parameters, with the trapping of hydrogen at phosphorus at elevated temperatures of particular importance. In addition, the influence of non-equilibrium conditions should also be investigated.

\section{ACKNOWLEDGMENTS}

Work at Oxford University has been supported by the U.K. Government through the International and Industrial Engagement Fund and the Supersilicon project (EP/ M024911/1), supported by the Engineering and Physical Sciences Research Council (EPSRC). Work at UNSW has been supported by the Australian Government through the Australian Renewable Energy Agency (ARENA) (ARENA 1-A060 and 1-SRI001) and the Australian Centre for Advanced Photovoltaics (ACAP), and the Australian Research Council (DE170100620). The views expressed herein are not necessarily the views of the Australian Government, and the Australian Government does not accept responsibility for any information or advice contained herein. P. Altermatt and B. Hallam would like to gratefully acknowledge support from the EPSRC Supersolar I\&I fund. Data for this paper are available at ora.ox.ac.uk.

\section{APPENDIX: MATHEMATICAL DETAILS OF THE MODEL}

The simulations in this paper were carried out using a MATLAB script. Using a finite element method at each location, values were determined for interstitial hydrogen in each charge state as well as for hydrogen bound to dopant ions and hydrogen dimers as shown in Fig. 10.

The flux between points $n$ and $n+1$ is given by

$$
J_{n}=J_{H^{+}, n}+J_{H^{0}, n}+J_{H^{-}, n}+J_{H_{2} A, n},
$$

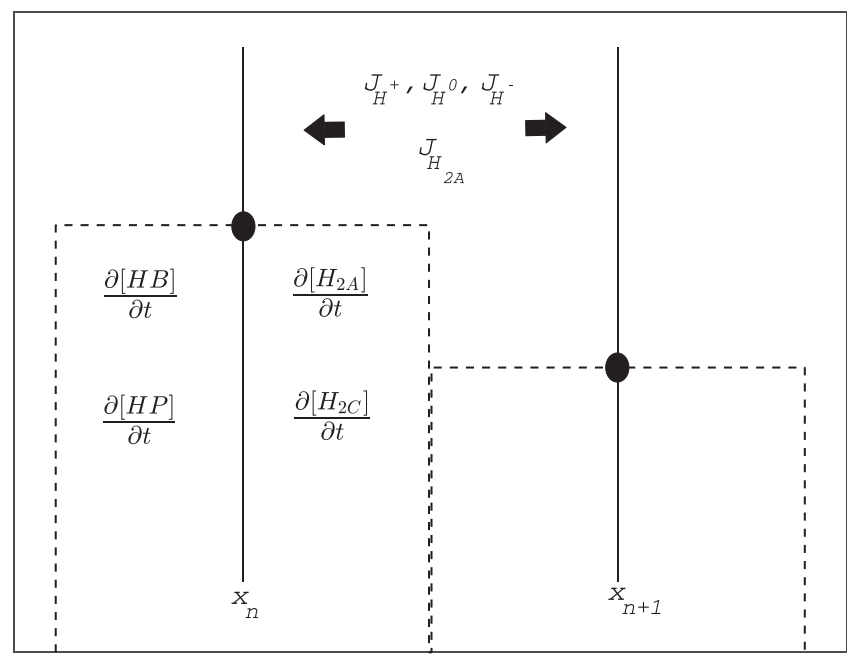

FIG. 10. Representation of hydrogen trapping and transport between finite elements. where

$$
\begin{gathered}
J_{H^{+}, n}=D_{H^{+}} \frac{\left[H_{n}^{+}\right]-\left[H_{n+1}^{+}\right]}{x_{n+1}-x_{n}}+\mu_{H^{+}} E_{n} \sqrt{\left[H_{n}^{+}\right]\left[H_{n+1}^{+}\right]}, \\
J_{H^{0}, n}=D_{H^{0}} \frac{\left[H_{n}^{0}\right]-\left[H_{n+1}^{0}\right]}{x_{n+1}-x_{n}}, \\
J_{H^{-}, n}=D_{H^{-}} \frac{\left[H_{n}^{-}\right]-\left[H_{n+1}^{-}\right]}{x_{n+1}-x_{n}}-\mu_{H^{-}} E_{n} \sqrt{\left[H_{n}^{-}\right]\left[H_{n+1}^{-}\right]}, \\
J_{H_{2} A}=D_{H_{2} A} \frac{\left[H_{2 A, n}\right]-\left[H_{2 A, n+1}\right]}{x_{n+1}-x_{n}} .
\end{gathered}
$$

From Eq. (A2) and (A4), it may be observed that diffusion between locations is calculated based on the difference in values for each charge state of hydrogen, while drift for locations is calculated using the geometric mean of the values for $\mathrm{H}^{+}$and $\mathrm{H}^{-}$. This was preferred to the arithmetic mean due to handling situations with large differences in interstitial hydrogen concentration, such as during the initial stages of in-diffusion.

The total change in interstitial hydrogen concentration at point $n$ is thus

$$
\begin{aligned}
\frac{\partial\left[H_{n}\right]}{\partial t}= & \frac{J_{n-1}-J_{n}}{x_{n+1}-x_{n-1}}-\frac{\partial[H B]}{\partial t}-\frac{\partial[H P]}{\partial t}-2 \frac{\partial\left[H_{2 A}\right]}{\partial t} \\
& -2 \frac{\partial\left[H_{2 C}\right]}{\partial t}
\end{aligned}
$$

where the rate of change of hydrogen trapped at dopants and dimers is given by Eqs. (7), (8), (11), and (12). The simulations were performed on a non-uniform domain of $20 \mu \mathrm{m}$ depth. The left boundary conditions were defined by a user set constant flux into the front surface, which was either $1 \times 10^{13}$ atoms $/ \mathrm{cm}^{2} / \mathrm{s}$ or 0 . At the rear surface, a Neumann boundary conditions was applied with zero flux out. While this limit on the domain is smaller than most solar cell thicknesses and can lead to an erroneous increase in bulk hydrogen concentration, this effect is negligible in our simulations and does not affect the general behaviour.

The overall system is strongly coupled to the interstitial hydrogen concentration and is mathematically stiff. This system was defined over a non-uniform vector in $\mathrm{x}$, with spacing ranging from $5 \mathrm{~nm}$ at the surface to $100 \mathrm{~nm}$ in the bulk. This system of equations was solved with a normalized tolerance criterion of $0.1 \%$ evaluated against the 2 nd order backwards differentiation formula in the interstitial hydrogen concentration

$$
H_{i, n}=\left(1+\frac{\Delta t_{n}^{2}}{3 \Delta t_{n+1}^{2}}\right) H_{i, n-1}-\frac{\Delta t_{n}^{2}}{3 \Delta t_{n+1}^{2}} H_{i, n-2}+\frac{2}{3} \Delta t_{n} \frac{\partial H_{i}}{\partial t},
$$

where $H_{i}$ is the total interstitial $\left(\mathrm{H}^{+}+\mathrm{H}^{0}+\mathrm{H}^{-}\right)$hydrogen concentration at each point and $\Delta t$ is the timestep. Since the system is strongly coupled with interstitial hydrogen, the most dynamic species this was sufficient to achieve convergence. In order to increase the size of time-steps that fulfilled this tolerance, a single Newton-Raphson iteration was 
performed in the interstitial hydrogen concentration, with accompanying normalization of the bound forms of hydrogen performed to fulfil continuity conditions. If a simulation step failed to meet the tolerance criteria with one iteration, it was discarded and the time-step halved for the next simulation step. While more than one iteration improved the convergence of the results, it was computationally expensive. In contrast, increasing the tolerance criteria improved the simulation speed, but led to larger fluctuations in the outputs, in particular, the bound concentrations of hydrogen.

When a simulation successfully met the tolerance criteria, the program moved to the next step with a $5 \%$ increase in time-step. In this way, the time-steps increased throughout the simulation until they reached the limit for which sufficient convergence could be achieved. This was found to be heavily temperature and structure dependent. For simulations using the heavy diffusion profile, the average time-step at $300{ }^{\circ} \mathrm{C}$ was $3.5 \mu$ s compared with $29 \mathrm{~ns}$ at $700^{\circ} \mathrm{C}$.

The electric potential and field within the structure, along with the concentration of electrons and holes was calculated every 500 time-steps using a simple 1D equilibrium Poisson solver. ${ }^{118}$ Replacing this with a non-equilibrium solver will be necessary for simulations using carrier generation or applied bias to manipulate the internal electric fields and hydrogen charge states. The effective doping at each node was taken as

$$
\begin{aligned}
& N_{D . e f f}=N_{D}+\left[H^{+}\right]-[H P], \\
& N_{\text {A.eff }}=N_{A}+\left[H^{-}\right]-[H B] .
\end{aligned}
$$

Incomplete ionisation was not considered in these simulations. While this may mean that the doping profile at $300{ }^{\circ} \mathrm{C}$ and above is slightly different than the electrically active profile measured at room temperature, the maximum difference is predicted to be less than $25 \%$ at doping concentrations between $1 \times 10^{18}$ and $1 \times 10^{19}$ atoms $/ \mathrm{cm}^{3}$, and smaller again outside this range. ${ }^{100}$ Furthermore, differences between temperatures of $300{ }^{\circ} \mathrm{C}$ and $700{ }^{\circ} \mathrm{C}$ as used in these simulations would be negligible.

Storing the data for each simulation step was found to be impractical with a personal computer. Instead, only the past two time-steps (required for the backwards differentiation formula) were kept, and every 20000 time-steps, the data for each variable was written to an output. These output files contained up to 20000 entries for simulations carried out at $700{ }^{\circ} \mathrm{C}$, down to $2000-3000$ at $300^{\circ} \mathrm{C}$, due to the difference in time-steps for which the tolerance criteria could be met. The longest simulations then contained up to $4 \times 10^{8}$ time-steps, which took several days to simulate on a personal computer. One of the future goals for this model is to reduce this time using more efficient code.

${ }^{1}$ F. Duerinckx and J. Szlufcik, Sol. Energy Mater. Sol. Cells 72(1-4), 231-246 (2002).

${ }^{2}$ M. Stavola, F. Jiang, S. Kleekajai, L. Wen, C. Peng, V. Yelundur, A. Rohatgi, G. Hahn, L. Carnel, and J. Kalejs, MRS Online Proc. Libr. 1210 (2009).

${ }^{3}$ R. Lüdemann, Mater. Sci. Eng., B 58(1-2), 86-90 (1999).
${ }^{4}$ B. J. Hallam, P. G. Hamer, S. R. Wenham, M. D. Abbott, A. Sugianto, A. M. Wenham, C. E. Chan, G. Xu, J. Kraiem, J. Degoulange, and R. Einhaus, IEEE J. Photovoltaics 4(1), 88-95 (2014).

${ }^{5}$ A. G. Aberle, Prog. Photovoltaics 8(5), 473-487 (2000).

${ }^{6}$ M. Sheoran, D. S. Kim, A. Rohatgi, H. Dekkers, G. Beaucarne, M. Young, and S. Asher, Appl. Phys. Lett. 92(17), 172107 (2008).

${ }^{7}$ T. G. Allen, J. Bullock, Q. Jeangros, C. Samundsett, Y. Wan, J. Cui, A. Hessler-Wyser, S. De Wolf, A. Javey, and A. Cuevas, Adv. Energy Mater. 7(12), 1602606 (2017).

${ }^{8}$ X. Yang, P. Zheng, Q. Bi, and K. Weber, Sol. Energy Mater. Sol. Cells 150, 32-38 (2016)

${ }^{9}$ S. De Wolf, A. Descoeudres, Z. C. Holman, and C. Ballif, Green 2(1), 7-24 (2012)

${ }^{10}$ B. Hallam, D. Chen, M. Kim, B. Stefani, B. Hoex, M. Abbott, and S. Wenham, Phys. Status Solidi A 214(7), 1700305 (2017).

${ }^{11}$ A. Liu, C. Sun, V. Markevich, A. Peaker, J. D. Murphy, and D. Macdonald, J. Appl. Phys. 120(19), 193103 (2016).

${ }^{12}$ M. Al-Amin and J. D. Murphy, J. Appl. Phys. 119(23), 235704 (2016).

${ }^{13}$ C. Chan, T. H. Fung, M. Abbott, D. Payne, A. Wenham, B. Hallam, R. Chen, and S. Wenham, Sol. RRL 1(2), 1600028 (2017).

${ }^{14}$ C. E. Chan, D. N. Payne, B. J. Hallam, M. D. Abbott, T. H. Fung, A. M. Wenham, B. S. Tjahjono, and S. R. Wenham, IEEE J. Photovoltaics 6(6), 1473-1479 (2016).

${ }^{15}$ D. Payne, C. Chan, B. Hallam, B. Hoex, M. Abbott, S. Wenham, and D. Bagnall, Phys. Status Solidi RRL 10(3), 237-241 (2016).

${ }^{16}$ K. Krauß, A. A. Brand, F. Fertig, S. Rein, and J. Nekarda, IEEE J. Photovoltaics 6(6), 1427-1431 (2016).

${ }^{17}$ P. Hamer, B. Hallam, M. Abbott, C. Chan, N. Nampalli, and S. Wenham, Sol. Energy Mater. Sol. Cells 145, 440-446 (2016).

${ }^{18}$ D. Bredemeier, D. Walter, S. Herlufsen, and J. Schmidt, AIP Adv. 6(3), 035119 (2016).

${ }^{19}$ M. Vaqueiro-Contreras, V. P. Markevich, M. Halsall, A. Peaker, P. Santos, J. Coutinho, S. Öberg, L. Murin, R. Falster, J. Binns, E. V. Monakhov, and B. G. Svensson, Phys. Status Solidi RRL 11(8), 1700133 (2017).

${ }^{20}$ V. Markevich, M. V. Contreras, J. Mullins, M. Halsall, B. Hamilton, L. Murin, R. Falster, J. Binns, E. Good, and J. Coutinho, paper presented at the 2016 IEEE 43rd Photovoltaic Specialists Conference (PVSC) (2016).

${ }^{21}$ M. A. Jensen, A. E. Morishige, J. Hofstetter, D. B. Needleman, and T. Buonassisi, IEEE J. Photovoltaics 7(4), 980-987 (2017).

${ }^{22}$ N. M. Johnson, F. A. Ponce, R. A. Street, and R. J. Nemanich, Phys. Rev. B 35(8), 4166-4169 (1987).

${ }^{23}$ S. Steingrube, P. P. Altermatt, D. S. Steingrube, J. Schmidt, and R. Brendel, J. Appl. Phys. 108(1), 014506 (2010).

${ }^{24}$ C. Chan, P. Hamer, G. Bourret-Sicotte, R. Chen, A. Ciesla, B. Hallam, D. Payne, R. S. Bonilla, and S. Wenham, Sol. RRL 1(11), 1700129 (2017).

${ }^{25}$ J. I. Pankove, D. E. Carlson, J. E. Berkeyheiser, and R. O. Wance, Phys. Rev. Lett. 51(24), 2224-2225 (1983).

${ }^{26}$ C. T. Sah, J. Y. C. Sun, and J. J. T. Tzou, Appl. Phys. Lett. 43(2), 204-206 (1983).

${ }^{27}$ N. Johnson, C. Herring, and D. Chadi, Phys. Rev. Lett. 56(7), 769 (1986).

${ }^{28}$ T. Zundel and J. Weber, Phys. Rev. B 43(5), 4361-4372 (1991).

${ }^{29}$ V. V. Voronkov and R. Falster, Phys. Status Solidi B 254(6), 1600779 (2017).

${ }^{30}$ V. V. Voronkov and R. Falster, Phys. Status Solidi A 214(7), 1700287 (2017).

${ }^{31}$ C. Sun, F. E. Rougieux, and D. Macdonald, J. Appl. Phys. 117(4), 045702 (2015).

${ }^{32}$ P. Hamer, B. Hallam, S. Wenham, and M. Abbott, IEEE J. Photovoltaics 4(5), 1252-1260 (2014).

${ }^{33}$ H. J. Lee, M. G. Kang, S. J. Choi, G. H. Kang, J. M. Myoung, and H.-E. Song, Curr. Appl. Phys. 13(8), 1718-1722 (2013).

${ }^{34}$ S. J. Choi, G. J. Yu, G. H. Kang, J. C. Lee, D. Kim, and H.-E. Song, Renewable Energy 54, 96-100 (2013).

${ }^{35} \mathrm{~S}$. Dubois, T. Turmagambetov, J.-P. Garandet, H. Lignier, and N. Enjalbert, Sol. Energy Mater. Sol. Cells 157(Suppl. C), 558-564 (2016).

${ }^{36} \mathrm{P}$. I. Widenborg and A. G. Aberle, J. Cryst. Growth 306(1), 177-186 (2007).

${ }^{37}$ S. J. Pearton, J. W. Corbett, and T. S. Shi, Appl. Phys. A: Mater. Sci. Process. 43(3), 153-195 (1987).

${ }^{38}$ J. K. Holt, D. G. Goodwin, A. M. Gabor, F. Jiang, M. Stavola, and H. A. Atwater, Thin Solid Films 430(1-2), 37-40 (2003).

${ }^{39}$ F. Jiang, M. Stavola, A. Rohatgi, D. Kim, J. Holt, H. Atwater, and J. Kalejs, Appl. Phys. Lett. 83(5), 931-933 (2003).

${ }^{40}$ N. Johnson, J. Walker, C. Doland, K. Winer, and R. Street, Appl. Phys. Lett. 54(19), 1872-1874 (1989). 
${ }^{41}$ M. J. Keevers, A. Turner, U. Schubert, P. A. Basore, and M. A. Green, paper presented at the 20th European Photovoltaic Solar Energy Conference (2005).

${ }^{42}$ B. Sopori, Y. Zhang, R. Reedy, K. Jones, Y. Yanfa, M. Al-Jassim, B. Bathey, and J. Kalejs, paper presented at the Conference Record of the Thirty-First IEEE Photovoltaic Specialists Conference (2005).

${ }^{43}$ B. L. Sopori, X. Deng, J. P. Benner, A. Rohatgi, P. Sana, S. K. Estreicher, Y. K. Park, and M. A. Roberson, Sol. Energy Mater. Sol. Cells 41-42, 159-169 (1996)

${ }^{44}$ J. Schmidt, A. Merkle, R. Brendel, B. Hoex, M. Van De Sanden, and W. Kessels, Prog. Photovoltaics 16(6), 461-466 (2008).

${ }^{45}$ B. Hoex, J. Schmidt, P. Pohl, M. Van de Sanden, and W. Kessels, J. Appl. Phys. 104(4), 044903 (2008).

${ }^{46}$ B. Hoex, S. Heil, E. Langereis, M. Van de Sanden, and W. Kessels, Appl. Phys. Lett. 89(4), 042112 (2006)

${ }^{47}$ G. Dingemans and W. Kessels, J. Vac. Sci. Technol. A 30(4), 040802 (2012)

${ }^{48}$ Y.-C. Kim, H.-H. Park, J. S. Chun, and W.-J. Lee, Thin Solid Films 237(1), 57-65 (1994).

${ }^{49}$ G. Dingemans, F. Einsele, W. Beyer, M. Van de Sanden, and W. Kessels, J. Appl. Phys. 111(9), 093713 (2012).

${ }^{50}$ H. Stein, V. Wells, and R. Hampy, J. Electrochem. Soc. 126(10), 1750-1754 (1979).

${ }^{51}$ L. Cai, A. Rohatgi, D. Yang, and M. El-Sayed, J. Appl. Phys. 80(9), 5384-5388 (1996).

${ }^{52}$ C. Boehme and G. Lucovsky, J. Non-Cryst. Solids 299-302, 1157-1161 (2002)

${ }^{53}$ C. Boehme and G. Lucovsky, J. Appl. Phys. 88(10), 6055-6059 (2000).

${ }^{54}$ J.-F. Lelièvre, E. Fourmond, A. Kaminski, O. Palais, D. Ballutaud, and M. Lemiti, Sol. Energy Mater. Sol. Cells 93(8), 1281-1289 (2009).

${ }^{55}$ H. Dekkers, G. Beaucarne, M. Hiller, H. Charifi, and A. Slaoui, Appl. Phys. Lett. 89(21), 211914 (2006).

${ }^{56}$ C. G. Van de Walle and J. Neugebauer, Nature 423(6940), 626-628 (2003).

${ }^{57}$ B. E. Deal, J. Electrochem. Soc. 121(6), 198C-205C (1974).

${ }^{58}$ S. R. Hofstein, IEEE Trans. Electron Devices 14(11), 749-759 (1967)

${ }^{59}$ J. Pankove, R. Wance, and J. Berkeyheiser, Appl. Phys. Lett. 45, 1100 (1984).

${ }^{60}$ S. Lindekugel, H. Lautenschlager, T. Ruof, and S. Reber, in 23rd EUPVSEC (2008).

${ }^{61}$ Y. Qiu, O. Kunz, A. Fejfar, M. Ledinský, B. Teik Chan, I. Gordon, D. Van Gestel, S. Venkatachalm, and R. Egan, Sol. Energy Mater. Sol. Cells 122, 31-39 (2014)

${ }^{62}$ S. Glunz, F. Feldmann, A. Richter, M. Bivour, C. Reichel, H. Steinkemper, J. Benick, and M. Hermle, paper presented at the 31st European Photovoltaic Solar Energy Conference and Exhibition (2015).

${ }^{63}$ C. Herring, N. M. Johnson, and C. G. Van de Walle, Phys. Rev. B 64(12), 125209 (2001)

${ }^{64}$ A. Van Wieringen and N. Warmoltz, Physica 22(6-12), 849-865 (1956).

${ }^{65}$ R. Rizk, P. de Mierry, D. Ballutaud, M. Aucouturier, and D. Mathiot, Phys. Rev. B 44(12), 6141-6151 (1991).

${ }^{66}$ D. Mathiot, Phys. Rev. B 40(8), 5867 (1989).

${ }^{67}$ S. Estreicher, A. Docaj, M. Bebek, D. Backlund, and M. Stavola, Phys. Status Solidi A 209(10), 1872-1879 (2012).

${ }^{68}$ B. Sopori, Y. Zhang, and N. M. Ravindra, J. Electron Mater. 30(12), 1616-1627 (2001)

${ }^{69}$ N. M. Johnson and C. Herring, Phys. Rev. B 46(23), 15554-15557 (1992).

${ }^{70}$ T. Zundel and J. Weber, Phys. Rev. B 46(4), 2071-2077 (1992).

${ }^{71}$ Y. V. Gorelkinskii and N. Nevinnyi, Mater. Sci. Eng., B 36(1-3), 133-137 (1996).

${ }^{72}$ K. Bonde Nielsen, B. B. Nielsen, J. Hansen, E. Andersen, and J. U. Andersen, Phys. Rev. B 60(3), 1716-1728 (1999).

${ }^{73}$ A. J. Tavendale, D. Alexiev, and A. A. Williams, Appl. Phys. Lett. 47(3), 316-318 (1985).

${ }^{74}$ S. K. Estreicher, C. H. Seager, and R. A. Anderson, Appl. Phys. Lett. 59(14), 1773-1775 (1991).

${ }^{75}$ T. Zundel and J. Weber, Phys. Rev. B 39(18), 13549-13552 (1989).

${ }^{76}$ J. Zhu, N. Johnson, and C. Herring, Phys. Rev. B 41(17), 12354 (1990).

${ }^{77}$ N. Yarykin, Phys. B: Condens. Matter 404(23-24), 5093-5095 (2009).

${ }^{78}$ C. E. Dube and J. I. Hanoka, paper presented at the Conference Record of the Thirty-First IEEE Photovoltaic Specialists Conference (2005).

${ }^{79}$ B. J. Hallam, P. G. Hamer, S. Wang, L. Song, N. Nampalli, M. D. Abbott, C. E. Chan, D. Lu, A. M. Wenham, and L. Mai, Energy Procedia 77, 799-809 (2015).
${ }^{80}$ C. G. Van de Walle and J. Neugebauer, Phys. Rev. B 52(20), R14320 (1995).

${ }^{81}$ A. J. Morris, C. J. Pickard, and R. Needs, Phys. Rev. B 78(18), 184102 (2008).

${ }^{82}$ Y. K. Park, S. K. Estreicher, C. W. Myles, and P. A. Fedders, Phys. Rev. B 52(3), 1718-1723 (1995).

${ }^{83}$ M. A. Roberson and S. K. Estreicher, Phys. Rev. B 49(24), 17040-17049 (1994).

${ }^{84}$ S. B. Zhang and W. B. Jackson, Phys. Rev. B 43(14), 12142-12145 (1991).

${ }^{85}$ S. K. Estreicher, Mater. Sci. Eng., R 14(7-8), 319-412 (1995).

${ }^{86}$ M. Matsubara, J. Godet, and L. Pizzagalli, Phys. Rev. B 82(2), 024107 (2010).

${ }^{87}$ S. T. Pantelides and F. Reboredo, Solid State Phenom. 69, 83-92 (1999).

${ }^{88}$ O. Velichko, Y. Shaman, and A. Fedotov, Phys. Status Solidi C 6(8), 1979-1982 (2009).

${ }^{89}$ N. H. Nickel, G. B. Anderson, N. M. Johnson, and J. Walker, Phys. Rev. B 62(12), 8012-8015 (2000).

${ }^{90}$ J. Heyman, J. Ager III, E. Haller, N. Johnson, J. Walker, and C. Doland, Phys. Rev. B 45(23), 13363 (1992).

${ }^{91}$ N. M. Johnson, D. K. Biegelsen, and M. D. Moyer, Appl. Phys. Lett. 40(10), 882-884 (1982).

${ }^{92}$ N. H. Nickel, W. B. Jackson, and J. Walker, Phys. Rev. B 53(12), 7750-7761 (1996).

${ }^{93}$ N. H. Nickel, N. M. Johnson, and W. B. Jackson, Appl. Phys. Lett. 62(25), 3285-3287 (1993).

${ }^{94}$ W. B. Jackson, N. M. Johnson, C. C. Tsai, I. W. Wu, A. Chiang, and D. Smith, Appl. Phys. Lett. 61(14), 1670-1672 (1992).

${ }^{95}$ S. K. Estreicher, J. L. Hastings, and P. A. Fedders, Phys. Rev. B 57(20), R12663-R12665 (1998).

${ }^{96}$ R. Fair and J. Tsai, J. Electrochem. Soc. 124(7), 1107-1118 (1977).

${ }^{97}$ N. M. Johnson and C. Herring, Phys. Rev. B 38(2), 1581-1584 (1988).

${ }^{98}$ P. I. Widenborg, J. W. Weber, M. L. Terry, and A. G. Aberle, paper presented at the Technical Digest 15th International Photovoltaic Science and Engineering Conference, Shanghai (2005).

${ }^{99}$ H. Li, K. Kim, B. Hallam, B. Hoex, S. Wenham, and M. Abbott, Front. Energy 11(1), 42-51 (2017).

${ }^{100}$ P. Altermatt, A. Schenk, and G. Heiser, J. Appl. Phys. 100(11), 113715 (2006).

${ }^{101}$ S. Solmi and D. Nobili, J. Appl. Phys. 83(5), 2484-2490 (1998).

${ }^{102}$ S. Hu, P. Fahey, and R. Dutton, J. Appl. Phys. 54(12), 6912-6922 (1983).

${ }^{103}$ R. Müller, J. Benick, N. Bateman, J. Schön, C. Reichel, A. Richter, M. Hermle, and S. W. Glunz, Sol. Energy Mater. Sol. Cells 120(A), 431-435 (2014).

${ }^{104}$ K. Chang and D. Chadi, Phys. Rev. B 40(17), 11644 (1989).

${ }^{105}$ ITRPV, 2017

${ }^{106}$ H. Wagner, A. Dastgheib-Shirazi, B. Min, A. E. Morishige, M. Steyer, G. Hahn, C. del Cañizo, T. Buonassisi, and P. P. Altermatt, J. Appl. Phys. 119(18), 185704 (2016).

${ }^{107}$ B. Min, H. Wagner, A. Dastgheib-Shirazi, A. Kimmerle, H. Kurz, and P. P. Altermatt, Phys. Status Solidi RRL 8(8), 680-684 (2014).

${ }^{108}$ V. Shanmugam, J. Cunnusamy, A. Khanna, P. K. Basu, Y. Zhang, C. Chen, A. F. Stassen, M. B. Boreland, T. Mueller, and B. Hoex, IEEE J. Photovoltaics 4(1), 168-174 (2014).

${ }^{109}$ I. B. Cooper, K. Tate, J. S. Renshaw, A. F. Carroll, K. R. Mikeska, R. C. Reedy, and A. Rohatgi, IEEE J. Photovoltaics 4(1), 134-141 (2014).

${ }^{110}$ A. W. Blakers, A. Wang, A. M. Milne, J. Zhao, and M. A. Green, Appl. Phys. Lett. 55(13), 1363-1365 (1989).

${ }^{111}$ M. A. Green, Sol. Energy Mater. Sol. Cells 143, 190-197 (2015).

${ }^{112}$ T. Dullweber, S. Gatz, H. Hannebauer, T. Falcon, R. Hesse, J. Schmidt, and R. Brendel, Prog. Photovoltaics 20(6), 630-638 (2012).

${ }^{113}$ S. Wilking, A. Herguth, and G. Hahn, J. Appl. Phys. 113(19), 194503-194506 (2013)

${ }^{114} \mathrm{~K}$. Münzer, paper presented at the Proceedings of the 24th European Photovoltaic Solar Energy Conference (2009).

${ }^{115}$ W. Duan, S. Yuan, Y. Sheng, W. Cai, Z. Zhang, Y. Chen, Y. Yang, P. P. Altermatt, P. J. Verlinden, and Z. Feng, in 32nd European PV Solar Energy Conference and Exhibition, Munich, Germany (2016), pp. 399-402.

${ }^{116}$ M. Al-Amin and J. D. Murphy, IEEE J. Photovoltaics 7(1), 68-77 (2017).

${ }^{117}$ A. Peral, A. Dastgheib-Shirazi, V. Fano, J. C. Jimeno, G. Hahn, and C. del Cañizo, IEEE J. Photovoltaics 7(1), 91-96 (2017).

${ }^{118}$ D. Vasileska, Nanohub, 2010 